\title{
Precipitation Processes
}

Silke Trömel ${ }^{1,2}$, Clemens Simmer ${ }^{1}$, Ulrich Blahak ${ }^{3}$, Armin Blanke ${ }^{1}$, Florian Ewald ${ }^{4}$, Michael Frech ${ }^{5}$, Mathias Gergely ${ }^{5}$, Martin Hagen ${ }^{4}$, Sabine Hörnig ${ }^{6}$, Tijana Janjic ${ }^{7}$, Heike Kalesse ${ }^{6}$, Stefan Kneifel ${ }^{8}$, Christoph Knote ${ }^{7,9}$, Jana Mendrok ${ }^{3}$, Manuel Moser ${ }^{10,4}$, Gregor Möller ${ }^{7}$, Kai Mühlbauer ${ }^{1}$, Alexander Myagkov $^{11}$, Velibor Pejcic ${ }^{1}$, Patric Seifert ${ }^{12}$, Prabhakar Shrestha ${ }^{1}$, Audrey Teisseire ${ }^{12}$, Leonie von Terzi ${ }^{8}$, Eleni Tetoni ${ }^{4}$, Teresa Vogl ${ }^{6}$, Christiane Voigt ${ }^{10,4}$, Yuefei Zeng ${ }^{7}$, Tobias Zinner ${ }^{7}$, Johannes Quaas ${ }^{6}$

\footnotetext{
${ }^{1}$ Institute for Geosciences, Department of Meteorology, University of Bonn, Bonn, 53121, Germany

${ }^{2}$ Laboratory for Clouds and Precipitation Exploration, Geoverbund ABC/J, Bonn, 53121, Germany

${ }^{3}$ Deutscher Wetterdienst (DWD), Offenbach, 63067, Germany

${ }^{4}$ Institute for Physics of the Atmosphere, DLR, Oberpfaffenhofen, 82234, Germany

${ }^{5}$ Deutscher Wetterdienst (DWD), Observatorium Hohenpeißenberg, Hohenpeißenberg, 82383, Germany

${ }^{6}$ Institute for Meteorology, Universität Leipzig, Leipzig, 04103, Germany

${ }^{7}$ Meteorological Institute Munich, Ludwig-Maximilians-Universität München, 80333, Germany

${ }^{8}$ Institute of Geophysics and Meteorology, University of Cologne, 50969, Germany

${ }^{9}$ Faculty of Medicine, University of Augsburg, Augsburg, 86159 Germany

${ }^{10}$ Institute for Physics of the Atmosphere, University Mainz, Mainz, 55099, Germany

${ }^{11}$ Radiometer Physics GmbH, Meckenheim, 53340, Germany

${ }^{12}$ Leibniz Institute for Tropospheric Research (TROPOS), 04318 Leipzig, Germany
}

Correspondence to: Silke Trömel (silke.troemel@uni-bonn.de)

Abstract. Cloud and precipitation processes are still the main source of uncertainties in numerical weather prediction and climate change projections. The Priority Program "Polarimetric Radar Observations meet Atmospheric Modelling (PROM)“, funded by the German Research Foundation (Deutsche Forschungsgemeinschaft, DFG), is guided by the hypothesis, that many uncertainties relate to the lack of observations suitable to challenge the representation of cloud and precipitation processes in atmospheric models. Such observations can, however, nowadays be provided e.g. by the recently installed dual-polarization C band weather radar network of the German national meteorological service in synergy with cloud radars and other instruments at German supersites and similar national networks increasingly available worldwide. While polarimetric radars potentially provide valuable in-cloud information e.g. on hydrometeor type, quantity, and microphysical cloud and precipitation processes, and atmospheric models employ increasingly higher moment microphysical modules, still considerable knowledge gaps exist in the interpretation of the observations and large uncertainties in the optimal microphysics model process formulations. PROM 
is a coordinated interdisciplinary effort to intensify the use of polarimetric radar observations in data assimilation, which requires a thorough evaluation and improvement of parametrizations of moist processes in atmospheric models. As an overview article of the inter-journal special issue "Fusion of radar polarimetry and numerical atmospheric modelling towards an improved understanding of cloud and precipitation processes", it outlines the knowledge achieved in PROM during the past two years and gives perspectives for the next four years.

\section{Introduction and Objectives of the priority program}

The main source of uncertainty in numerical weather prediction (NWP) and climate change projections are cloud and precipitation processes. A major part of these uncertainties can be attributed to missing observations suitable to challenge the representation of cloud and precipitation processes employed in atmospheric models. Since several years a wealth of new information on precipitation microphysics and generating processes can be gained from observations from polarimetric weather radars and their synergistic analysis at different frequencies. The dual-polarization upgrade of the United States National Weather Service (NWS) S-Band Weather Surveillance Radar 1988 Doppler (WSR-88D) network was completed in 2013. Germany finished upgrading its C-band network to polarimetry in 2015 in parallel to other European countries. Together with measurements from cloud radars and other instrumentation available at supersites and research institutions their synergetic exploitation enables for the first time a thorough evaluation and potential improvement of current microphysical parameterizations based on detailed multi-frequency remote-sensing observations. Data assimilation merges observations and models for state estimation as a prerequisite for prediction and can be considered as a smart interpolation between observations while exploiting the physical consistency of atmospheric models as mathematical constraints.

Considerable knowledge gaps still exist, however, both in radar polarimetry and atmospheric models, which still impede the full exploitation of the triangle radar polarimetry - atmospheric models - data assimilation and called for a coordinated interdisciplinary effort. The German Research Foundation (Deutsche Forschungsgemeinschaft, DFG) responded to this call and established the Priority Program „Polarimetric Radar Observations meet Atmospheric Modelling (PROM)“; its first 3year funding period started 2019, which will be followed by a second funding period starting in 2022. PROM will exploit the synergy of polarimetric radar observations and state-of-the-art atmospheric models to better understand moist processes in the atmosphere, and to improve their representation in climate- and weather prediction models. The overarching goal is to extend our scientific understanding at the verges of the three disciplines radar polarimetry - atmospheric models - data assimilation for better predictions of precipitating cloud systems. To approach this goal the initiators of PROM at the Universities of Bonn and Leipzig in Germany identified the following five objectives (see also Trömel et al. 2018): 
1) Exploitation of radar polarimetry for quantitative process detection in precipitating clouds and for model evaluation,

2) Improvement of cloud and precipitation schemes in atmospheric models based on process fingerprints detectable in polarimetric observations,

3) Monitoring of the energy budget evolution due to phase changes in the cloudy, precipitating atmosphere for a better understanding of its dynamics,

4) Generation of precipitation system analyses by assimilation of polarimetric radar observations into atmospheric models for weather forecasting, and

5) Radar-based detection of the initiation of convection for the improvement of thunderstorm prediction.

In the first funding period, 14 projects (see https://www2.meteo.uni-bonn.de/spp2115) distributed over Germany contribute to at least one of these objectives. In most projects, a radar meteorologist works together with a modeller in order to successfully combine expert knowledge from both research fields. This overview article of the ACP/AMT/GMD inter-journal special issue entitled "Fusion of radar polarimetry and numerical atmospheric modelling towards an improved understanding of cloud and precipitation processes" outlines methodologies developed and results achieved from a selection of the projects during the past two years and provides overall perspectives for the next four years. The paper is organized as follows: Section 2 explains prevailing challenges in the representation of clouds in atmospheric models, while Sect. 3 provides methodologies to extend our insight in the microphysics of clouds and precipitation by exploiting radar polarimetry. Section 4 addresses the fusion of both disciplines - numerical modelling and radar polarimetry - via model evaluation either in radar observation space using forward operators or using microphysical retrievals. First conclusions for improved model parameterizations and for a better representation of model uncertainty in the process of radar data assimilation are drawn. Section 5 provides a summary and perspectives for the following years.

\section{Representation of clouds in atmospheric models}

The representation of cloud- and precipitation processes in atmospheric models is a central challenge for NWP and climate projections (e.g., Boucher et al., 2013; Bauer et al., 2015); they also impact offline hydrological models by significantly modulating the distribution of incoming solar radiation and precipitation and affecting the simulated hydrological processes such as evapotranspiration, runoff, and groundwater depths (e.g., Shrestha 2021). While the primitive equations provide a solid theoretical basis for atmospheric model dynamics, the key diabatic processes that drive energetics and thus circulation, are hardly resolved. These are the cloud microphysical processes acting at scales of micrometres and turbulent processes ranging from several to hundreds of meters. While significant progress has been achieved by high-resolution modelling at the coarser end of this range (e.g., Heinze et al., 2017; Stevens et al., 2020), the intricate and complex microphysical processes will still require parameterizations in any dynamic atmospheric model down to the scale of direct numerical simulations (e.g., Mellado et al., 2009). 
A key uncertainty in weather prediction and climate modelling results from the still rudimentary representation of moist processes and the diabatic heating/cooling they induce due to latent heat and their interaction with radiation. The generation and interpretation of past and future climate states has in addition to consider changes in microphysical processes due to anthropogenic aerosol acting e.g. as cloud condensation nuclei and ice nucleating particles. For short-term weather prediction, the location and evolution of convective events with lifetimes of hours or less are particularly challenging, while relatively slow moving and frontal systems with lifetimes of days show reasonable predictability (Alifieri et al., 2012). High-resolution simulations and observations of fronts point at their composition of small-scale filament-type short-lived convective features, but their importance for the system evolution (and predictability) is not yet fully understood.

Atmospheric modelling in Germany has recently seen substantial advances both in terms of cloud-resolving simulations in NWP mode and in the implementation of ice and mixed-phase precipitation formation processes. Traditionally, different model systems were used for NWP and climate modelling, which were also both heavily used in academic research. Research with the ECHAM model family originating from the NWP model of the European Centre for Medium-Range Weather Forecasts (ECMWF) focused on long-term climate integrations at horizontal resolutions of the order of $100 \mathrm{~km}$ (Stevens et al., 2013), and the COSMO model operated at horizontal resolutions down to $2.8 \mathrm{~km}$ was used for NWP and reanalysis studies. Both model families are currently replaced by the ICOsahedral Nonhydrostatic (ICON) modelling framework (Zängl et al., 2015) jointly developed by Max-Planck Institute for Meteorology and the German national meteorological service (Deutscher Wetterdienst, DWD). Its climate version (the ICON general circulation model, ICON GCM) inherited its physics package from the ECHAM model, and the NWP version incorporated the one from the COSMO model. A third version largely based on the COSMO physics package was developed for higher resolutions (Dipankar et al., 2015) and employs a large-eddy turbulence scheme (ICON-LEM). The latter is able to operate on large domains (Heinze et al., 2017; Stevens et al., 2020) and includes aerosol-cloud interactions (Costa-Surós et al., 2020). In PROM primarily the ICON variants are used.

In most atmospheric models, cloud and precipitation microphysical processes are represented by bulk microphysical schemes that distinguish between different hydrometeor classes and include their specific masses as prognostic variables while their size distributions are parameterized. Computationally much more demanding are so-called spectral-bin microphysics schemes (Khain et al., 2015), which evolve cloud- and precipitation particle size distributions discretized into size-interval bins. An example is the Hebrew University cloud model created by Khain et al. (2005) that treats both liquid and much more intricate ice crystal distributions. The model is employed by some of the PROM projects in addition to the liquid-only bin-microphysics model by Simmel et al. (2015) extended by the ice phase based on the scheme by Hashino and Tripoli (2007). For the simulation of the evolution of specific air volumes a Lagrangian particle model (McSnow; Brdar and Seifert, 2018) is used in PROM, that models ice and mixed-phase microphysical processes such as depositional growth, aggregation, riming, secondary ice generation, and melting closer to the real processes than bulk formulations. Microphysical processes including radiation- 
in radar observations - is instrumental for a full understanding and adequate representation of the microphysical processes in models. Advanced microphysical parameterizations such as spectral-bin or Lagrangian particle schemes are relevant for cloudresolving models and exploited for the development and improvement of bulk parametrizations. Scientific questions about global climate necessitate long model integrations and thus coarse spatial resolutions which require parametrizations of the spatial cloud variability; here PROM builds on assumptions employed in the global ICON model (ICON GCM) to predict fractional cloudiness (e.g., Quaas, 2012).

\section{Observational insights from polarimetric radar observations and remaining challenges}

DWD operates 17 state-of-the-art polarimetric Doppler C-band weather radars which provide a 3-D sampling of precipitation processes every five minutes. Together with the Doppler information from those systems, radar data are the backbone for precipitation and nowcasting products for all meteorological services. Although precipitation monitoring is still the most widespread application of weather radars, their upgrade to polarimetry worldwide not only improve precipitation estimates, their observations are also increasingly exploited for the evaluation and improvement of the representation of cloud- and precipitation processes in atmospheric models. Additional observations from cloud radars nowadays available at so-called supersites (in Germany e.g. the Jülich Observatory for Cloud Evolution - Core Facility; JOYCE-cf; Löhnert et al. 2015; http://www.cpex-lab.de), universities, and research facilities (e.g. the Leipzig Aerosol and Cloud Remote Observations System; LACROS; Bühl et al., 2013) open extended opportunities to inform and improve atmospheric models. The use of shorter wavelengths of cloud radars shifts the sensitivity of the observations towards smaller particles and partly increases the strength of the received polarimetric signals (e.g. $\mathrm{K}_{\mathrm{DP}}$ - the phase change between horizontal and vertical polarization per distance called specific differential change - scales with $\lambda^{-1}$ ), which allows for more detailed studies of ice and cloud microphysics. Polarimetric and multi-frequency radar observations allow even more to zoom in microphysical processes and provide a great data base for model evaluation, the improvement of microphysical parameterizations, and data assimilation, and thus have the potential to significantly improve both weather forecasts and climate predictions.

\subsection{Multi-frequency and spectral polarimetry for ice and cloud microphysics} polarImetry aNd super-parTicle modelling (IMPRINT) aims at improving our ice microphysical process understanding by using multi-frequency spectral radar polarimetric observations. Spectral polarimetry exploits in particular the different terminal velocities of hydrometeor types to quantify their contributions to the total measured polarimetric quantity; e.g. the strong polarimetric signals generated by small ice particles can be separated from the weak polarimetric contribution of large aggregates to the total measured differential reflectivity $Z_{\mathrm{DR}}$. The combination of spectral polarimetric with multi-frequency radar observations allows for the investigation of the evolution of particle sizes in detail. A common observable is the dual 
particles transition from the Rayleigh scattering to the non-Rayleigh scattering regime at the higher frequencies, the dualwavelength reflectance ratio (DWR) increases and thus indicates an increase of the mean size of the particle size distribution (e.g. Ori et al., 2020). Fig. 1a shows the DWR during snowfall at the ground observed at Ka and W band for 2019-01-22 over the "Jülich Observatory for Cloud Evolution - Core Facility" (JOYCE-cf). At about 15 UTC, the DWR-KaW strongly increases in about $2300 \mathrm{~m}$ height indicating the onset of strong aggregation. While DWR is sensitive to large aggregates, high $Z_{\mathrm{DR}}$ (the difference between horizontal and vertical radar reflectivity) indicates asymmetric particles (in case of frozen precipitation it signals small ice crystals). Since $\mathrm{Z}_{\mathrm{DR}}$ is an integral signal of the present particle size distribution (PSD), it is dominated by the larger aggregates and thus decreases at the height level where DWR-KaW starts to rise (Fig. 1b). $K_{D P}$ also starts rising at this level (Fig. 1c), which may indicate secondary ice production. The spectrally resolved DWR-KaW and $Z_{\mathrm{DR}}$ $\left(\mathrm{sZ} Z_{\mathrm{DR}}\right)$ at $15 \mathrm{UTC}$ are shown in Figs 1d-e for more detailed insights. Enhanced DWR-KaW on the left side of the spectrum indicates aggregates already present above $-15^{\circ} \mathrm{C}$ reaching maximum sizes at around $-10^{\circ} \mathrm{C}$. The width of the DWR-KaW spectrum starts to increase rapidly already at around $-17^{\circ} \mathrm{C}$ resulting in a secondary spectral mode at $-15^{\circ} \mathrm{C}$, and $\mathrm{s} \mathrm{ZR}_{\mathrm{DR}}$ reaches values of up to $3 \mathrm{~dB}$ for the slow falling particles. A possible interpretation of the bimodal DWR spectrum at increased $s Z_{\mathrm{DR}}$ and $\mathrm{K}_{\mathrm{DP}}$ is the fragmentation of delicate ice crystal structures, which have been found in laboratory studies to evolve close to $-17^{\circ} \mathrm{C}$ (Takahashi et al., 1995; Takahashi 2014). The fragmentation signal might not only relate to single crystals but could also be caused by dendritic structures growing at the surface of aggregates similar to the growth structures found on ice spheres at similar temperatures in the laboratory study by Takahashi (1993). polarimetric radar observations at C-and Ka-band (IcePolCKa) combines in a novel approach the observations of the Cband POLDIRAD at DLR, Oberpfaffenhofen, with those of the Ka-band miraMACS at LMU, Munich, to study convective cells with a focus on ice particle growth and its role in precipitation formation. Coordinated Range-Height-Indicator (RHI, varying elevation at constant azimuth) scans provide simultaneous measurements of the respective DWR (Fig. 2a) and $Z_{D R}$ (Fig. 2b) along the $23 \mathrm{~km}$ long cross-section between the two radar instruments while convective cells are tracked. The deviation from Rayleigh scattering with increasing ice crystal size is used to distinguish regions with larger ice crystals formed by riming or aggregation from regions with depositional growth indicated by enhanced DWR of reflectivities at the longer and shorter wavelength. While this technique provides valuable information on ice crystal size, the unknown ice crystal shape still leads to ambiguities in the identification and retrieval of ice microphysics. Here, simultaneous polarimetric measurements, like The measurements are compared with scattering calculations to identify ice crystal size and asphericity, which enters a retrieval algorithm currently in development. The polarimetric, multi-wavelength measurements are also used as a benchmark for precipitation formation in NWP models. A nested WRF setup covering the overlap area of both radars is used to simulate convective events with microphysical schemes of varying complexity. The Cloud-resolving model Radar SIMulator (CR-SIM; 
and $\mathrm{Z}_{\mathrm{DR}}$ (Fig. 2d). IcePolCKa has collected a 2-year dataset, which is currently used to analyze the performance of different microphysical schemes on a sound statistical basis. E.g. Fig. 2 illustrates that the predicted particle properties (P3) scheme (Morrison and Milbrandt, 2015) is able to produce DWR features of similar magnitude and variability compared to the observations while a realistic ice particle asphericity is still missing.

The PROM-project A seamless column of the precipitation process from mixed-phase clouds employing data from a polarimetric C-band radar, a microrain radar and disdrometers (HydroColumn) characterizes precipitation processes inside a vertical atmospheric column by combining polarimetric Doppler weather radar observations with co-located measurements from micro-rain radars, disdrometers and in-situ measurements, and by relating these high-resolution observations to the largescale atmospheric thermodynamics derived from NWP models. To date spectral analyses are mostly performed with cloud radars operating at shorter wavelengths (see previous paragraphs), but their applicability to the national C-band radar network offers prospects for operational area-wide applications, e.g. the identification of dominant precipitation particle growth process such as aggregation or riming. HydroColumn plans to provide the proof of concept that Doppler spectra measured at C-band provide beneficial microphysical process information. As an example, Fig. 3 shows quasi-vertical profiles (QVPs; Trömel et al., 2014; Ryzhkov et al., 2016) of polarimetric variables and Doppler spectra from birdbath scans for a stratiform precipitation event monitored with the Hohenpeißenberg C-band research radar (47.8014N, 11.0097E) of DWD together with in-situ particle images obtained by the Falcon research aircraft from the German Aerospace Center (DLR) during the BLUESKY campaign (Voigt et al., 2021) within the POLICE project (Sect. 3.2). In-situ measurements have been performed with the Cloud, Aerosol and Precipitation Probe CAPS (Kleine et al., 2018) integrated in a wing station on the Falcon flying within a horizontal distance of about $20 \mathrm{~km}$ from the radar site and within about $\pm 15 \mathrm{~min}$ of the radar measurements. The dendritic growth layer (DGL) centered around $-15{ }^{\circ} \mathrm{C}$ is characterized by $\mathrm{Z}_{\mathrm{DR}}$ maxima of $\sim 1 \mathrm{~dB}$ and $\mathrm{K}_{\mathrm{DP}}$ of $\sim 0.2^{\circ} \mathrm{km}^{-1}$, and a strong $\mathrm{Z}_{\mathrm{H}}$-increase towards lower levels (Fig. 3a). Particle images collected at temperatures colder than about $-15{ }^{\circ} \mathrm{C}$ indicate mostly small irregular ice particles with the number of larger particles increasing toward $-15^{\circ} \mathrm{C}$ (see levels L1 and L2 in Fig. 3c), and further down also reveal dendrites and plates (L3, L4). In general, aggregation and riming become highly effective particle growth mechanisms at temperatures around $-7^{\circ} \mathrm{C}$ (Libbrecht 2005) resulting in a reduction of $Z_{D R}$ (Fig. 3a). In this specific case study, the absence of secondary spectral modes in the Doppler spectra at C-band combined with relatively slow mean Doppler velocities above the melting layer suggests aggregation instead of riming as the dominant growth process (Fig. 3b). This is confirmed by insitu images showing irregular 3-D structures of occasionally very large size while no large supercooled liquid droplets required for significant riming were recorded (L6).

\subsection{Anthropogenic modifications of precipitation microphysics}

The PROM-project Polarimetry Influenced by CCN aNd INP in Cyprus and Chile (PICNICC) thrives to improve our understanding of aerosol effects on microphysical growth processes in mixed-phase clouds. PICNICC exploits unique remote- 
sensing datasets from the LACROS suite extended with ground-based remote sensing instruments of Leipzig University, Universidad de Magallanes (Punta Arenas), and Cyprus University of Technology (Limassol). Thus, dual-frequency polarimetric radar observations from the polluted, aerosol-burden Northern and from the clean, pristine Southern hemisphere can be contrasted for microphysical process studies. Since higher ice crystal concentrations favour aggregation, the latter is expected to be more frequent for high aerosol loads and accordingly higher ice nucleating particle (INP) concentrations, while riming should prevail when supercooled liquid layers are sustained due to a scarcity of INP. Evaluating this hypothesis requires the distinction between aggregation and riming processes in mixed-phase cloud systems. Fig. 4 demonstrates for 30 August 2019, when a deep mixed-phase cloud system passed the site, the capability of the LACROS suite when combined with a 94$\mathrm{GHz}$ Doppler radar at the low-aerosol site in Punta Arenas $\left(53^{\circ} \mathrm{S}, 71^{\circ} \mathrm{W}\right)$, Chile, to distinguish between aggregates and rimed particles. The pattern of the $94-\mathrm{GHz}$ radar reflectivity factor $\left(\mathrm{Z}_{\mathrm{c}}\right.$, Fig. $\left.4 \mathrm{a}\right)$ underlines the complex structure of the system. The height spectrogram of vertical-stare 94-GHz slanted linear depolarization ratio (SLDR, Fig. 4 e) from 08:30 UTC exhibits regions of changing shape signatures and multi-modality in the cloud radar Doppler spectra, where multiple hydrometeor populations coexist. From the RHI scans of SLDR and the co-cross correlation coefficient of horizontal and vertically polarized channels in the slanted basis $\rho_{\mathrm{s}}$ at 35-GHz (Fig. 4 b, c) the polarizability ratio $\xi_{\mathrm{c}}$ (Myagkov et al., 2016) is obtained (Fig. 4d), which allows to estimate a density-weighted hydrometeor shape. For the purpose of shape classification, SLDR is more suited compared to LDR. By slanding the polarization basis by $45^{\circ}$, the returned LDR signatures are much less sensitive to the canting angle distribution of the targets, especially at low elevation angles (Myagkov et al., 2016). The polarimetric RHI scans and the Doppler spectra data allow to retrieve the vertical profile of the hydrometeors: Columnar-shaped bullet rosettes are formed between $2.5 \mathrm{~km}$ height and cloud top as indicated in the RHI scans by an elevation-constant SLDR (Fig. 4b) and an increase of $\rho_{\mathrm{s}}$ with decreasing elevation (Fig. 4c). $\xi_{\mathrm{c}}$ is around 1.3 (Fig. 4d), which is characteristic for slightly columnar crystals. Already at around $3 \mathrm{~km}$ height $\left(-15\right.$ to $\left.-20^{\circ} \mathrm{C}\right)$ a decreasing elevation-dependence of $\rho_{\text {s }}$ suggests a more random particle orientation; here the W-band SLDR spectra (Fig. 4e) show reduced values, likely due to the co-existence of dendritic ice crystals, which are formed preferably in this temperature range and cause low SLDR at vertical-stare. The co-location of dendrites and columnar crystals can be explained by either splintering of the arms of the dendritic crystals or a mixing of

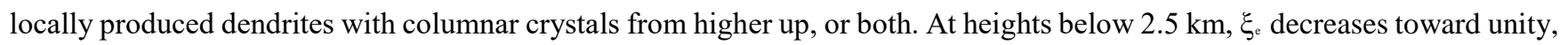
indicating the growth of isometric particles. Also the vertical-stare W-Band SLDR slowly decreases toward the cloud base, while fall velocities increase (Fig. 4e). Both features are characteristic for riming, which is corroborated by co-located lidar observation detecting liquid water in the cloud-base region (not shown). use and land-cover changes on precipitating cloud structure and its dynamics. A co-analysis of polarimetric radar observations 
models to reproduce them. The Terrestrial Systems Modeling Platform (TSMP; Shrestha et al., 2014; Gasper et al., 2014) developed by the DFG-funded Transregional Research Center TR32 (Simmer et al., 2015) was used to simulate a hailstorm observed on 5 July 2015 with the polarimetric X-band radar (BoXPol, e.g. Diederich et al., 2015a,b) passing the city of Bonn, Germany. Sensitivity simulations were conducted using large-scale aerosol perturbations and different land-cover types reflecting actual, reduced and enhanced human disturbances. While the differences in modelled precipitation in response to the prescribed forcing were below $5 \%$, the micro- and macrophysical pathways were found to differ, acting as a buffered system to the prescribed forcings (Stevens and Feingold, 2009; Seifert and Beheng, 2012). Fig. 5 shows vertical cross-section measured with BoXPol together with simulated $\mathrm{Z}_{\mathrm{H}}$ and $\mathrm{Z}_{\mathrm{DR}}$ for the TSMP simulations with actual land-cover but perturbed condensation nuclei $(\mathrm{CN})$ and ice nucleating particle (INP) concentrations. The Bonn Polarimetric Radar forward Operator, B-PRO, (Xie et al., 2021; Xie et al., 2016; Heinze et al., 2017) based on an early version of EMVORADO (Zeng et al., 2016) and further developed within the Operation Hydrometeors project jointly with the polarimetric version of EMVORADO (Mendrok et al., 2021; see also Sec. 3.1) has been applied to generate the synthetic variables. The vertical cross sections are compared at different times marked by the vertical grey bars in the time series of Convective Area Fraction (CAF, Fig. 5 a), defined as the ratio of area with $Z_{\mathrm{H}}>40 \mathrm{dBZ}$ (at $2 \mathrm{~km}$ a.g.l.) to total storm area. On average BoXPol observations show a bit higher CAF compared to the simulations. The evolution is always similar in terms of an initial increase and intensification in the second part of the observation period, where the experiment with maritime aerosols and low INP (Mar-lowIn) is closest to observations. All simulations show $\mathrm{Z}_{\mathrm{H}}$ and $\mathrm{Z}_{\mathrm{DR}}$ patterns comparable to BoXPol observations, however, the experiment with

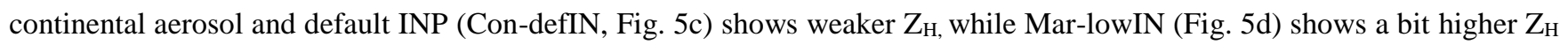
values compared to BoXPol (see Fig 5a). CN concentrations are $100 \mathrm{~cm}^{-3}$ for maritime and $1700 \mathrm{~cm}^{-3}$ for continental aerosol. Similarly, concentrations for dust, soot and organics are 162E $3 \mathrm{~m}^{3}, 15 \mathrm{E} 6 \mathrm{~m}^{3}$ and 177E6 $\mathrm{m}^{3}$, respectively, for default INP. For low/high INP, the concentration of soot and organics are decreased/increased by one order of magnitude. The experiment with continental aerosol and high INP concentration (Con-highIN, not shown) generates similar polarimetric moments like ConlowIN. All experiments show vertically extensive columns of (slightly) enhanced $\mathrm{Z}_{\mathrm{DR}}$, collocated with intense simulated updrafts reaching up to 13 to $14 \mathrm{~km}$ height. Indeed, those $\mathrm{Z}_{\mathrm{DR}}$-columns emerged recently as proxies for updraft strength and ensuing precipitation enhancement (Weissmann et al., 2014; Simmer et al., 2014; Kumjian et al., 2014), and research on their exploitation for nowcasting and data assimilation is ongoing. In Fig. 5c/d synthetic $Z_{\mathrm{DR}}$-columns are vertically extensive, while $Z_{\mathrm{DR}}$ values within the column stay below $0.3 \mathrm{~dB}$. BoXPol observations show $Z_{\mathrm{DR}}$-columns reaching up to $6 \mathrm{~km}$ height only but with $Z_{\mathrm{DR}}$ values exceeding $1 \mathrm{~dB}$. While $\mathrm{Z}_{\mathrm{DR}}$ values in the lower part of the columns are mostly generated by large raindrops, freezing drops and wet hail determine $Z_{D R}$ in the upper parts of the column (Kumjian et al., 2014; Snyder et al., 2015). The diverging appearance of observed and synthetic $Z_{\mathrm{DR}}$ columns may point to a deficiency in the treatment of raindrops undergoing freezing and motivates further research. Too rapid freezing of drops combined with graupel generated from the frozen drops may generate enhanced but still low $Z_{\mathrm{DR}}$ up to high altitudes. Following Ilotoviz et al. (2018) such attributes of $Z_{\mathrm{DR}}$ columns are highly determined by the vertical velocity, hail size, and aerosol concentration, e.g. higher $\mathrm{CN}$ concentrations 
Mar-lowIN (i.e. with lower $\mathrm{CN}$ concentration) shows a wider and a bit taller $\mathrm{Z}_{\mathrm{DR}}$ column together with a more intense $\mathrm{Z}_{\mathrm{H}}$ core (compare Fig. 5c/d). Further explanations, however, require an improved representation of the $\mathrm{Z}_{\mathrm{DR}}$-columns in the model.

\section{Fusion of radar polarimetry and atmospheric models}

Probably the most important and central tool for connecting polarimetric observations with numerical atmospheric models are observation operators, which generate virtual observations from the model state. The latter can be directly compared with the real observations and signatures of microphysical processes including their temporal evolution. Thus, the accuracy of precipitation and cloud parameterizations can be indirectly evaluated, and a data base established for model optimization. E.g. missing polarimetric process fingerprints (e.g. Kumjian, 2012) in the virtual observations may hint at model deficiencies, and model parameterizations can be adapted in order to increase the coherence between real and virtual observations. Moreover, appropriate observation operators are mandatory for the direct assimilation of observations using ensemble methods. However, bulk cloud microphysical parameterizations required for NWP models include assumptions on several critical parameters and processes to make up for lacking constraints from the governing numerical model. For example, in most operational bulk schemes the melting state as well as shape, microstructure, and orientation of the different hydrometeors are not prognostic (or not even implicitly assumed). These assumptions need also to be taken into account in observation operators in order to create meaningful virtual observations. An example are the inherently assumed particle size distributions and their relations to the prognostic moments. Moreover, bulk cloud microphysical schemes may only insufficiently approximate the natural variability and interaction between small sets of assumed hydrometeor classes and size distribution moments mainly tuned to get e.g. the surface precipitation right. Therefore, these current approximations in both numerical models and observation operators may translate into different sources of errors and biases of the simulated radar variables (e.g. Schinagl et al., 2019). An example can be seen in Figure 7, which will be discussed in Sect. 4.2.1. Such problems challenge both model evaluation and data assimilation. Central science questions are therefore the realism of the sensitivities of simulated radar variables to parameters in the observation operators and the models, and the effective approaches to the evaluation and improvement of moist processes parametrizations.

\subsection{Radar observation operators}

315 The PROM-project Operation Hydrometeors extends the up to now non-polarimetric radar observation operator 316 EMVORADO (Zeng et al., 2016; Blahak and de Lozar, 2020; Blahak, 2016) to polarimetry (Mendrok et al., 2021) called Pol317 EMVORADO in the following. EMVORADO has been designed to efficiently simulate volume scan measurements of entire 318 radar networks from the prognostic model state of an NWP model. PPI volume scans can be simulated for many radar stations simultaneously for direct comparisons with the radar observations. EMVORADO is part of both the COSMO and ICON NWP model's executable and access model state variables in memory. The code is MPI- and OpenMP-parallelized and thus fully 
drives. This enables large-scale real-time applications such as operational data assimilation and extensive NWP model verifications using whole radar networks at high temporal resolution. Its modular nature allows for relatively easy interface development to other NWP models. An offline framework is also available, which accesses model states of one model time step from hard disk. EMVORADO includes detailed modular schemes to simulate beam bending, beam broadening and melting effects, and allows users to choose for each process between computationally cheap and physically accurate options. The operator has been used for the assimilation of radar reflectivity with positive impact on precipitation forecasts (Bick et al., 2016; Zeng et al., 2018, 2019, 2020). Currently, DWD uses EMVORADO to assimilate 3D volumetric reflectivity and radial wind observations of its C-Band radar network. Key for this application is also the extensive use of precomputed lookup tables which relate Mie-reflectivity to hydrometeors and temperature. The effects of neglecting reflectivity weighting, beam broadening and fall speed on data assimilation have been investigated in a joint effort together with the PROM-project Representing model error and observation Error uncertainty for Data assimilation of POLarimetric radar measurements (REDPOL) (Zeng et al., 2021).

Pol-EMVORADO inherits all features of EMVORADO and expands them to polarimetric observables. This includes e.g. the different beam bending, broadening and smoothing schemes, the effective medium approximations allowing 1- and 2-layered hydrometeors with different water-ice-air mixing schemes and melting topologies, and the lookup table approach for an efficient access to polarimetric observables such as $\mathrm{Z}_{\mathrm{DR}}, \mathrm{LDR}, \rho_{\mathrm{HV}}$, and $\mathrm{K}_{\mathrm{DP}}$. Optionally, attenuation effects and specific and differential attenuation ( $A_{H}$ and $A_{D P}$, respectively) can be considered and further quantities derivable from the complex scattering amplitudes can easily be added. Scattering properties of spheroidal particles derived by one-layered (Mishchenko, 2000) and two-layered T-Matrix approaches (Ryzhkov et al., 2011) are used instead of the "spherical" Mie-theory used in EMVORADO. Assumptions on spheroid shape and orientation follow parametrizations introduced in Ryzhkov et al. (2011). The lookup table approach has been revised to accommodate the additional parameters necessary to derive the full set of polarimetric radar output.

Pol-EMVORADO is now incorporated into the official version of EMVORADO and can be run offline (i.e. stand-alone with model fields from data files) and online (i.e. within a COSMO or ICON run). Designed as a PPI volume scan observation operator for a radar network, its output can also be provided on NWP model grids. An example of a synthetic $\mathrm{Z}_{\mathrm{DR}}$ from the REDPOL project is given in Fig. 6 (see also Sec. 4.2.3). Applying Pol-EMVORADO (or the related B-PRO, see Sect. 3.2) within PROM several issues became evident. Assuming hydrometeors as homogeneous effective-medium particles (oblate spheroids) does not reproduce well the polarimetric signatures of low density hydrometeors like dendrites or aggregates as typical in snow when keeping their microphysical properties (e.g. aspect ratio, degree of orientation) within realistic - observed or model-predicted - ranges and consistent between different radar frequencies. This deficiency has been demonstrated and explained from electromagnetic theory by Schrom et al. (2018) and became also evident in the case study by Shrestha et al. (2021) and in Fig. 7, where $Z_{\mathrm{DR}}$ and $\mathrm{K}_{\mathrm{DP}}$ almost entirely lack the typical features in the snow-dominated layer between 2.5 and $5 \mathrm{~km}$ height. Orientation and shape of frozen and melting hydrometeors are very variable both in nature and in the assumptions used in observation operators, which 
translates in large uncertainties in polarimetric radar signatures (e.g., Matsui et al., 2019; Shrestha et al., 2021). To tackle these challenges, Pol-EMVORADO will include in the future interfaces to several scattering databases or other scattering models in order to enable more realistic cloud ice and aggregate snowflake scattering properties and allow for improvements or extensions of the polarimetry-related microphysical assumptions (shape/habit/microstructure, orientation and their distribution, e.g., Wolfensberger et al., 2018), particularly for (partly-)frozen hydrometeors. This will be taken up in PROM's $2^{\text {nd }}$ phase guided with Lagragian particle model information, as well as the test of Pol-EMVORADO in an operational data assimiliation environment.

\subsection{Model evaluation and improvements using forward simulations and microphysical retrievals}

\subsubsection{Convection-resolving simulations with COSMO}

In a joint effort, the PROM-projects Operation Hydrometeors and ILACPR evaluated simulated stratiform precipitation events in radar observation space and developed a sophisticated polarimetry-based hydrometeor classification and quantification for the evaluation of the representation of hydrometeors in numerical models. Based on a stratiform event monitored on 7 October 2014 with the Bonn polarimetric X-Band radar BoXPol, Fig. 7 illustrates the potential of using polarimetric observations for the evaluation and improvement of microphysical parametrisations. Fig. 7 a-f compare QVPs of measured and virtual $\mathrm{Z}_{\mathrm{H}}, \mathrm{Z}_{\mathrm{DR}}$, and $\mathrm{K}_{\mathrm{DP}}$ with the Bonn Polarimetric Radar forward Operator B-PRO (Xie et al., 2021) to forecasts simulated with COSMO version 5.1 using its 2-moment cloud microphysics scheme (itype_gscp=2683; Seifert and Beheng, 2016). Due to a small spatial shift of the precipitation event in the simulations, the observations at $50.7305 \mathrm{~N}, 7.0717 \mathrm{E}$ are compared with simulations at a close-by grid-point at 51.1 N, 7.0717 E. As demonstrated in Shrestha et al. (2021) using a similar stratiform precipitation event, COSMO tends to simulate considerable amounts of melting graupel partly reaching the surface, which results within and below the melting layer (ML) to higher synthetic $Z_{\mathrm{DR}}$ than observed (compare Fig. 7c/d). Above the ML, however, synthetic $Z_{\mathrm{DR}}$ already approaches $0 \mathrm{~dB}$ at around $6 \mathrm{~km}$ height, which indicates deficiencies in the ice-snow partitioning in COSMO and the approximation of snow particles as soft spheroids in B-PRO leading in too low polarimetric signals. While observed and simulated $\mathrm{Z}_{\mathrm{H}}$ is comparable in terms of structure and magnitude, except a more pronounced observed ML, larger differences exist with respect to $K_{\mathrm{DP}}$ above the ML (Fig. 7e/f). While observations show bands of enhanced $\mathrm{K}_{\mathrm{DP}}$ within the so-called dendritic growth layer centred around $-12^{\circ} \mathrm{C}$, the simulated $\mathrm{K}_{\mathrm{DP}}$ is very weak indicating lower crystal concentration and early aggregates compared to observations (e.g. Moisseev et al., 2015). Comparison of ice water content (IWC) above the ML retrieved from measured $\mathrm{K}_{\mathrm{DP}}$ and differential reflectivity in linear scale $\mathrm{Z}_{\mathrm{dr}}$, i.e. IWC( $\mathrm{K}_{\mathrm{DP}}$, magnitudes (compare Fig. 7 g/h) in line with the lower simulated $K_{D P}$. Overall, Fig. 7 supports the hypothesis of a too strong graupel production in simulations. Operation Hydrometeors also developed a robust radar-based hydrometeor classification (HMC) and mixing ratio quantification algorithm following Grazioli et al. (2015) and Besic et al. $(2016,2018)$ for the evaluation of the representation of hydrometeors in NWC models (standard output is the dominant hydrometeor type only). 
BoXPol observations above does not indicate graupel below the ML (Fig. 8a), while COSMO simulates a pronounced, thick graupel layer (Fig. 8b) including some melting graupel particles reaching the ground around 1:45 UTC. Applied to the virtual observations, however, it does not reproduce a graupel layer of similar intensity (Fig. 8c), probably caused by a too strong $Z_{\mathrm{H}}$ and temperature influence (compare with Fig. 7) relative to the polarimetric variables in the classification scheme which needs further investigation. For the case study in Shrestha et al. (2021) the simulated graupel was even more pronounced and sensitivity experiments were performed to guide model improvement. Increasing the minimum critical particle diameter $\mathrm{D}_{\text {crit, }}$ which is required for self-collection of ice particles (aggregation) increased/improved the ice-snow partitioning, and a lower temperature threshold for snow and ice riming, $\mathrm{T}_{\text {rime }}$, considerably reduced the graupel production.

Comparing state-of-the-art polarimetric retrievals of liquid water content (LWC), ice water content (IWC), particle number concentration $\mathrm{N}_{\mathrm{t}}$ and mean particle diameter $\mathrm{D}_{\mathrm{m}}$ (e.g. Ryzhkov et al., 2018; Ryzhkov and Zrnic, 2019; Bukovčić et al., 2020; Reimann et al., 2021; Trömel et al., 2019) with their simulated counterparts can also be used for evaluating NWP models and for data assimilation (Carlin et al., 2016). E.g. Fig. $7 \mathrm{~g} / \mathrm{h}$ shows for the case study discussed earlier higher IWC( $\left.\mathrm{K}_{\mathrm{DP}}, \mathrm{Z}_{\mathrm{dr}}\right)$ than simulated by COSMO. For more solid conclusions about possible model errors - and for the use of retrieved quantities for data assimilation, the retrieval uncertainties must be estimated. The analysis of data collected in the ice regions of tropical convective clouds indicates e.g., that IWC $\left(\mathrm{K}_{\mathrm{DP}}, \mathrm{Z}_{\mathrm{dr}}\right)$ yields a root-mean-square error of of $0.49 \mathrm{gm}^{-3}$ with the bias within $6 \%$ (Nguyen et al., 2017; 2019).

The PROM-project Polarimetric signatures of ice microphysical processes and their interpretation using in-situ

observations and cloud modeling POLICE evaluates radar retrievals and models using in particular in-situ observations of microphysical cloud parameters from the research aircrafts HALO (e.g. Wendisch et al., 2016; Voigt et al., 2017) and Falcon (e.g. Voigt et al., 2010; Voigt et al., 2014; Flamant et al., 2017). Currently, ground-based polarimetric radar measurements and aircraft in-situ data from the Olympic Mountain Experiment OLYMPEX (Houze et al., 2017; Heymsfield et al., 2018) are exploited to investigate riming processes and to evaluate retrievals of ice water content (IWC), particle number concentration

$412 \mathrm{~N}_{\mathrm{t}}$, and mean particle diameter $\mathrm{D}_{\mathrm{m}}$ (e.g. Ryzhkov et al., 2018; Ryzhkov and Zrnic, 2019; Bukovčić et al., 2020). The 413 OLYMPEX mission took place on the Olympic Peninsula of Washington State (USA) from November 2015 through February 414 2016. The science aircraft University of North Dakota's (UND) Cessna Citation II equipped with an in-situ cloud payload 415 overpassed the National Science Foundation (NSF) Doppler On Wheels (DOW, mobile polarimetric X-band radar with about $41660 \mathrm{~km}$ range and $74 \mathrm{~m}$ radial resolution), placed in the Chehalis Valley at Lake Quinault $\left(47.48^{\circ} \mathrm{N}, 123.86^{\circ} \mathrm{W}, 64 \mathrm{~m}\right.$ altitude) 417 performing RHI scans within an azimuthal sector of $22^{\circ}$. Measurements and microphysical retrievals of the DOW and the 418 Citation, respectively, are currently evaluated and will then be compared at matched space-time coordinates for several flight 419 transects. 


\subsubsection{Climate simulations with ICON-GCM}

A major part of the uncertainties in representing clouds and precipitation in atmospheric models can be attributed to unresolved variability that affects resolved variables via non-linear processes. Current climate model horizontal resolutions are of the order of $100 \mathrm{~km}$. But even for NWP models, which have resolutions between $10 \mathrm{~km}$ for global and $1 \mathrm{~km}$ for regional simulations, most cloud processes remain unresolved. The project Climate model PArameterizations informed by RAdar $(\boldsymbol{P A R A})$ evaluates and improves the representation of cloud and precipitation processes in particular for climate models and focuses on precipitation formation in ice clouds. Since most surface precipitation over continents and extra-tropical oceans involve the ice phase (Mülmenstädt et al., 2015; Field and Heymsfield, 2015) its reliable representation is paramount and thus the focus of PARA. Microphysical parameterizations typically consider only the mean cloud liquid or ice water content to compute process rates, which causes biases in all non-linear processes including radiation (e.g., Cahalan 1994; Carlin et al., 2002) and precipitation formation (e.g., Pincus and Klein, 2000). Realistic results thus require the tuning of process rates (e.g., Rotstayn 2000) or realistic estimates of subgrid-scale cloud variability and its inclusion in the process parameterizations. PARA tries to exploit to this goal inherent model assumptions for treating fractional cloudiness. Since the early works of Sommeria and Deardorff (1977), atmospheric models assume or predict some notion of subgrid-scale variability of relative humidity. Some models do so by predicting cloud fraction (e.g., Tiedtke 1993), others use a diagnostic representation of the subgridscale probability density function (PDF) of total water specific humidity, $\mathrm{q}_{t}$ (e.g., Sundqvist et al., 1989; Smith 1990; Le Treut and $\mathrm{Li}$, 1991; Rosch et al., 2015). Another option is to utilize a prognostic PDF of $\mathrm{q}_{\mathrm{t}}$ by assuming a functional form and predicting the shape parameters of the PDF (e.g., Tompkins 2002; Neggers 2009). The German climate and weather prediction model ICON in its version dedicated to climate simulations (general circulation model version; ICON-GCM) inherits the representation of physical processes from its predecessor ECHAM6 (Stevens et al., 2013) and uses the Sundqvist et al. (1989) parameterization for a diagnostic PDF of the total-water specific humidity, q.

As a first step, PARA analysed the implied PDF of cloud ice using satellite observations from combined CloudSat-CALIPSO radar-lidar satellite observations (DARDAR, Delanoë et al., 2014). Interestingly, a first direct comparison of IWC profiles obtained from DARDAR with polarimetric retrievals based on the ground-based BoXPol radar show an overall good agreement, except for columns with an integrated ice water path IWP $>1 \mathrm{~kg} \mathrm{~m}^{-2}$. In these regions pronounced polarimetric signatures result in high IWC at higher altitudes, which are neither reproduced by reflectivity-only retrievals nor by the DARDAR retrievals. The statistics are currently evaluated on a larger data base, which is also used to investigate the impact on the parameterizations in ICON-GCM. In the second step, a stochastic parameterisation approach is taken to allow for an unbiased computation of cloud microphysical process rates on average. Based on the cumulative distribution function (CDF), a random number generator draws from the CDF according to the simulated likelihood a plausible value of the specific ice mass based on which the microphysical process is computed. This specifically considers the formation of solid precipitation (snow) from ice clouds via aggregation and accretion processes (Lohmann and Roeckner, 1996; Stevens et al., 2013), and 
subsequently the evaporation of precipitation below the clouds. The result of the revised aggregation parameterization is shown in Fig. 9. The increased aggregation rate, which is a super-linear function of the specific cloud ice, $\mathrm{q}_{\mathrm{i}}$, leads to an average decrease in $\mathrm{q}_{\mathrm{i}}$. The aggregation rate is directly linked to the accretion rate, which lowers the effect of $\mathrm{q}_{\mathrm{i}}$ decrease. An investigation of the influence of the revised aggregation parameterization on the different microphysical process rates - which are related to the ice phase - is currently performed. A detailed evaluation of the new versus old parameterizations with groundbased polarimetric radar is on its way, and will in particular focus on the time scales of evaporation of precipitation below the cloud.

\subsubsection{Data assimilation}

461 Within an idealized framework, Jung et al. $(2008,2010)$ and Zhu et al. (2020) demonstrated benefits of assimilating simulated 462 polarimetric data for the estimation of microphysical state variables. Up to now, however, direct assimilation of real 463 polarimetric data poses great challenges due to the deficiencies of cloud and precipitation schemes in NWP models in 464 realistically representing and providing the necessary information (optimally the distribution of particle size, shape and orientations in all model grid boxes) required by a polarimetric radar observation operator and therefore causing large representation error (Janjic et al., 2018). Both, specification of model error to examine uncertainty in microphysics and specification of observation error for polarimetric radar observations that include estimates of the representation error, are investigated in the PROM-project REDPOL. For the assimilation of radar reflectivity with an ensemble Kalman filter, several approaches for including model errors during data assimilation were explored, including 1) additive noise with samples representing large-scale uncertainty (see Zeng et al., 2018), 2) combination of large scale and unresolved scale uncertainty (Zeng et al., 2019), and finally 3) adding to these warm bubble triggering of convective storms in case they are missing in the one hour forecast but present in corresponding observations (Zeng et al., 2020). Applying Pol-EMVORADO to the analysis obtained by assimilating radar reflectivity (German C-Band network), Fig. 6 illustrates the resulting differences of these three techniques in $Z_{\mathrm{DR}}$-space. Obviously, synthetic $\mathrm{Z}_{\mathrm{DR}}$ values depend on the strategy used to specify the model error, putting another weight to the argument that assimilation of radar reflectivity alone is not sufficient to constrain the estimation of microphysical state variables and that polarimetric information is required in addition. First results in this direction were reported by Putnam et al. (2019), who assimilated $Z_{\mathrm{DR}}$ below the melting layer but reported problems in assimilation of $\mathrm{K}_{\mathrm{DP}}$ data.

\section{Summary and Perspectives}

480 The Priority Programme Polarimetric Radar Observations meet Atmospheric Modelling (PROM) (SPP 2115, 481 https://www2.meteo.uni-bonn.de/spp2115/) was established in April 2017 by the Senate of the Deutsche 482 Forschungsgemeinschaft (DFG, German Research Foundation) and is designed to run for six years. PROM is a coordinated 483 effort to foster partnerships between cloud modelers and radar meteorologists and thus to accelerate the exploitation of 
polarimetric weather radars to improve the representation of cloud and precipitation processes in numerical models. The first funding phase engaged in an as complete as possible exploitation and understanding of nation-wide polarimetric measurements complemented by state-of-the measurement devices and techniques available at supersites. Bulk polarimetric measurements available over Germany are complemented with multi-frequency observations and spectral polarimetry for detailed studies of ice and cloud microphysics. Thus, for the first time, modellers hold three-dimensional microphysics-related observational data in their hands to improve parameterisations. Key tools for the fusion of radar polarimetry and atmospheric modelling, e.g. the Monte-Carlo Lagrangian particle model McSnow and the polarimetric observation operator Pol-EMVORADO have been developed. PROM started with detailed investigations of the representation of cloud and precipitation processes in the COSMO and ICON atmospheric models exploiting the polarimetric B-PRO and EMVORADO observation operators. First improvements of the 2-moment cloud- and precipitation microphysics scheme are made and more are expected in phase 2. Also intercomparisons of microphysic schemes in radar space have been performed. Phase 1 further developed microphysical retrievals, determined their uncertainties and started their exploitation for model evaluation and radar-informed parameterizations. Developed prerequisites pave the way to finally exploit polarimetry for indirect and direct data assimilation in the upcoming second funding phase.

Some tools developed in Phase 1, however, still require refinement in Phase 2. The T-matrix calculations for electromagnetic scattering by spheroidal particles represent only a crude approximation to frozen and mixed-phase hydrometeors, especially for pristine ice particles and aggregate snowflakes at cloud radar wavelengths. It is not possible to reproduce observed polarimetric signatures of snow with the T-Matrix approach (i.e. homogeneous ice-air spheroids) and realistic microphysics (shape, orientation). Refinements include interfacing to a new discrete dipole approximation (DDA)based scattering data base for realistic ice and snow particles for all relevant weather radar wavelengths and improvements of the melting scheme of graupel and hail.

Based on the made progress the fusion of radar polarimetry and atmospheric modelling can be approached even more aggressively in Phase 2. While objective 1 received most attention in Phase 1, more projects will exploit now the observational insights and tools developed to finally improve parameterizations and assimilate polarimetric information, i.e. more emphasis will be put on Objectives 2 and 4 in Phase 2. Direct assimilation of polarimetric variables remains challenging, because NWP models need to realistically represent and provide the necessary information required by a polarimetric radar observation operator; ideally the distribution of particle size, shape and orientation would be required in all model grid boxes. Indirect assimilation of polarimetric information (e.g. microphysical retrievals, and process signatures), however, is less demanding to

512 the model and should be pursued in parallel. Modern Bayesian data assimilation techniques are sensitive to both model- and forward operator biases, so that further work on these issues is of great importance for a successful data assimilation.

\section{Data availability}


The data presented in this paper are available through the authors upon request. Polarimetric radar data from the operational in addition.

\section{Author contributions}

Silke Trömel had the initial idea and mainly organized and structured the joint publication. Silke Trömel, Johannes Quaas, and Clemens Simmer formed the editorial team consolidating the text. All authors contributed to specific sections of the paper and commented on the paper.

\section{Competing interests}

Johannes Quaas is editor of ACP. The authors declare to have no additional conflict of interest.

\section{Special issue statement}

This article is the overview article of the ACP/AMT/GMD inter-journal special issue "Fusion of radar polarimetry and numerical atmospheric modelling towards an improved understanding of cloud and precipitation processes". It is not associated with a conference.

\section{Acknowledgments}

534 We gratefully acknowledge the funding of the German Research Foundation (DFG) to initialize the special priority program on the Fusion of Radar Polarimetry and Atmospheric Modelling (SPP-2115, PROM). The work of contributing authors was carried out in the framework of the projects Operation Hydrometeors (Grants TR 1023/16-1 and BL 945/2-1), ILACPR (Grant

537 SH 1326/1-1), POLICE (Grants TR 1023/13-1 and VO 1504/5-1), PARA (Grants QU 311/21-1 and TR 1023/15-1), 538 HydroColumn (FR 4119/1-1), REDPOL (Grant JA 1077/5-1), and PICNICC (Grants KA 4162/2-1 and SE 2464/1-1).

\section{References}

541 Alfieria, L., Thielen, J., and Pappenberger, J.: Ensemble hydro-meteorological simulation for flash flood early detection in 542 southern Switzerland, J. Hydrol., 424, 143-153, doi:10.1016/j.jhydrol.2011.12.038, 2012.

543 Bauer, P., Thorpe, A., and Brunet, G.: The quiet revolution of numerical weather prediction, Nature 525, 47-55, 544 doi:10.1038/nature14956, 2015.

545 Besic, N., Gehring, J., Praz, C., Figueras i Ventura, J., Grazioli, J., Gabella, M., Germann, U., and Berne, A.: Unraveling 546 hydrometeor mixtures in polarimetric radar measurements, Atmos. Meas. Tech., 11, 4847-4866, doi:10.5194/amt-11-4847$547 \quad 2018,2018$. 
Besic, N., Figueras i Ventura, J., Grazioli, J., Gabella, M., Germann, U., and Berne, A.: Hydrometeor classification through statistical clustering of polarimetric radar measurements: A semisupervised approach. Atmospheric Measurement Techniques, 9(9), pp.4425-4445, 2016

551

Bick, T., Simmer, C., Trömel, S., Wapler, K., Stephan, K., Blahak, U., Zeng, Y., and Potthast, R.: Assimilation of 3D-radar Reflectivities with an Ensemble Kalman Filter on the Convective Scale, Quart. J. Roy. Meteor. Soc., 142, 1490-1504, 2016.

Blahak, U.: RADAR_MIE_LM and RADAR_MIELIB - Calculation of Radar Reflectivity from Model Output, COSMO Technical Report No. 28, Consortium for Small Scale Modeling (COSMO), available online http://www.cosmomodel.org/content/model/documentation/techReports/docs/techReport28.pdf, 2016.

Blahak, U. and De Lozar, A.: EMVORADO - Efficient Modular VOlume scan RADar Operator. A User's Guide, Deutscher Wetterdienst, available online http://www.cosmo-model.org/content/model/documentation/core/emvorado_userguide.pdf, 2020.

Brdar, S. and Seifert, A.: McSnow: A Monte-Carlo Particle Model for Riming and Aggregation of Ice Particles in a Multidimensional Microphysical Phase Space, J. Adv. Model. Earth Syst., 10(1), 187-206, doi:10.1002/2017MS001167, 2018.

Boucher, O., et al.: Clouds and aerosols, in Climate Change 2013: The Physical Science Basis. Contribution of Working Group I to the Fifth Assessment Report of the Intergovernmental Panel on Climate Change, edited by T. Stocker, et al., pp. 571-658, Cambridge University Press, Cambridge, United Kingdom and New York, NY, USA, 2013.

Bukovčić, P., Ryzhkov, A., and Zrnić, D.: Polarimetric Relations for Snow Estimation—Radar Verification, Journal of Applied Meteorology and Climatology, 59(5), 991-1009, doi:10.1175/JAMC-D-19-0140.1, 2020

Bühl, J., Seifert, P., Wandinger, U., Baars, H., Kanitz, T., Schmidt, J., Myagkov, A., Engelmann, R., Skupin, A., Heese, B., Klepel, A., Althausen, D., and Ansmann, A.: LACROS: The Leipzig Aerosol and Cloud Remote Observations System, in: SPIE Remote Sensing, edited by Comeron, A., Kassianov, E. I., Schäfer, K., Stein, K., and Gonglewski, J. D., p. 889002, Dresden, Germany, doi:10.1117/12.2030911, 2013.

Cahalan, R. F.: Bounded cascade clouds: albedo and effective thickness, Nonlinear Proc. In Geophysics., 1, 156-167, 1994.

Carlin, B., et al.: High-cloud horizontal inhomogeneity and solar albedo bias, J. Climate, 15, 2321 - 2339, 2002. 
Carlin, J. T., Ryzhkov, A. V., Snyder, J. C., and Khain, A.: Hydrometeor Mixing Ratio Retrievals for Storm-Scale Radar Data Assimilation: Utility of Current Relations and Potential Benefits of Polarimetry, Monthly Weather Review 144(8), 2981-3001, doi:10.1175/MWR-D-15-461 0423.1., 2016. and attribution of aerosol-cloud interactions in large-domain large-eddy simulations with the ICOsahedral Non-hydrostatic model, Atmos. Chem. Phys., 20, 5657-5678, doi:10.5194/acp-20-5657-2020, 2020.

Delanoë, J., Heymsfield, A. J., Protat, A., Bansemer, A., and Hogan, R. J.: Normalized particle size distribution for remote sensing application, J. Geophys. Res. Atmos., 119, 4204-4227, doi:10.1002/2013JD020700, 2014.

Diederich, M., Ryzhkov, A., Simmer, C., Zhang, P., and Trömel, S.: Use of specific attenuation for rainfall measurement at X-band radar wavelengths - Part 1: Radar calibration and partial beam blockage estimation, Journal of Hydrometeorology, 16, 2, 487-502, doi: 10.1175/JHM-D-14-0066.1, 2015a.

Diederich, M., Ryzhkov, A., Simmer, C., Zhang, P., and Trömel, S.: Use of specific attenuation for rainfall measurement at X-band radar wavelengths - Part 2: Rainfall estimates and comparison with rain gauges, Journal of Hydrometeorology, 16, 2, 503-516, doi: 10.1175/JHM-D-14-0067.1, 2015b.

Dipankar, A., Stevens, B., Heinze, R., Moseley, C., Zängl, G., Giorgetta, M., and Brdar, S.: Large eddy simulations using the

Field, P. R. and Heymsfield, A. J.: Importance of snow to global precipitation, Geophys. Res. Lett., 42, 9512-9520, 608 doi:10.1002/2015GL065497, 2015.

Gasper, F., Görgen, K., Shrestha, P., Sulis, M., Rihani, J., Geimer, M., and Kollet, S.: Implementation and scaling of the fully coupled Terrestrial Systems Modeling Platform (TerrSysMP v1. 0) in a massively parallel supercomputing environment-a case study on JUQUEEN (IBM Blue Gene/Q). Geoscientific model development, 7(5), 2531-2543, 2014. 
Flamant, C., Knippertz, P., Fink, A.H., Akpo, A., Brooks, B., Chiu, C.J., Coe, H., Danuor, S., Evans, M., Jegede, O., Kalthoff, Ayoola, M., Batenburg, A.M., Bessardon, G., Borrmann, S., Brito, J., Bower, K., Burnet, F., Catoire, V., Colomb, A., Denjean, P., Sauer, D., Smith, V., Stratmann, G., Taylor, J.W., Voigt, C., and Yoboué, V.: The Dynamics-Aerosol-Chemistry-Cloud Interactions in West Africa Field Campaign: Overview and Research Highlights, Bull. Amer. Meteor. Soc., 99, 83-104, https://doi.org/10.1175/BAMS-D-16-0256.1, 2018

Hashino, T., and Tripoli, G. J.: The Spectral Ice Habit Prediction System (SHIPS). Part I: Model Description and Simulation of the Vapor Deposition Process, Journal of the Atmospheric Sciences, 64(7), 2210-2237, doi:10.1175/JAS3963.1, 2007.

626

Heinze, R., Dipankar, A., Henken, C. C., Moseley, C., Sourdeval, O., Trömel, S., Xie, X., Adamidis, P., Ament, F., Baars, H. Barthlott, C., Behrendt, A., Blahak, U. , Bley, S. , Brdar, S., Brueck, M., Crewell, S., Deneke, H., Girolamo, P. D., Evaristo, R., Fischer, J., Frank, C., Friederichs, P., Göcke, T., Gorges, K., Hande, L., Hanke, M., Hansen, A., Hege, H.-C., Hoose, C., Jahns, T., Kalthoff, N., Klocke, D., Kneifel, S., Knippertz, P., Kuhn, A., Laar, T., Macke, A., Maurer, V., Mayer, B., Meyer, C. I., Muppa, S. K., Neggers, R. A. J., Orlandi, E., Pantillon, F. , Pospichal, B., Röber, N., Scheck, L., Seifert, A., Seifert, P., Senf, F. , Siligam, P., Simmer, C., Steinke, S., Stevens, B., Wapler, K., Weniger, M., Wulfmeyer, V., Zängl, G., Zhang, D., and Quaas, J.: Large-eddy simulations over Germany using ICON: A comprehensive evaluation, Quart. J. Roy. Meteorol. Soc., 143, 69-100, doi:10.1002/qj.2947, 2017.

Heymsfield, A., Bansemer, A., Wood, N. B., Liu, G., Tanelli, S., Sy, O. O., Poellot, M., and Liu, C.: Toward Improving Ice Water Content and Snow-Rate Retrievals from Radars. Part II: Results from Three Wavelength Radar-Collocated In Situ Measurements and CloudSat-GPM-TRMM Radar Data, Journal of Applied Meteorology and Climatology, 57(2), 365-389. Retrieved Apr 6, 2021, from https://journals.ametsoc.org/view/journals/apme/57/2/jamc-d-17-0164.1.xml, 2018.

Ilotoviz, E., Khain, A., Ryzhkov, A. V., and Snyder, J. C.: Relation between Aerosols, Hail Microphysics, and ZDR Columns, J. Atmos. Sci., 75, 1755-1781, doi:10.1175/JAS-D-17-0127.1, 2018.

Janjic, T., Bormann, N., Bocquet, M., Carton, J. A., Cohn, S. E., Dance, S. L., Losa, S. N., Nichols, N. K., Potthast, R., Waller, J. A., and Weston, P.: On the representation error in data assimilation, Q. J. R. Meteorol. Soc., 144:713, 1257-1278, 2018. 
Jung, Y., Xue, M., Zhang, G., and Straka, J.: Assimilation of simulated polarimetric radar data for a convective storm using ensemble Kalman filter. Part II: Impact of polarimetric data on storm analysis, Mon. Wea. Rev., 136, 2246-2260, doi:10.1175/2007MWR2288.1, 2008.

Jung, Y., Xue, M., and Zhang, G.: Simultaneous Estimation of Microphysical Parameters and the Atmospheric State Using Simulated Polarimetric Radar Data and an Ensemble Kalman Filter in the Presence of an Observation Operator Error, Mon.

Wea. Rev., 138, 539-562, doi:10.1175/2009MWR2748.1, 2010.

Khain, A., Rosenfeld, D., and Pokrovsky, A.: Aerosol impact on the dynamics and microphysics of convective clouds, Q. J.

R. Meteorol. Soc., 131, 2639-2663, doi:10.1256/qj.04.62, 2005.

657

Khain, A. P., Beheng, K. D., Heymsfield, A., Korolev, A., Krichak, S. O., Levin, Z., Pinsky, M., Phillips, V., Prabhakaran, T.,

Teller, A., et al.: Representation of microphysical processes in cloud-resolving models: Spectral (bin) microphysics versus bulk parameterization, Rev. Geophys., 53, 247-322, doi:10.1002/2014RG000468, 2015.

Kleine, J., Voigt, C., Sauer, D., Schlager, H., Scheibe, M., Kaufmann, S. , Jurkat-Witschas, T., Kärcher, B., and Anderson B.: In situ observations of ice particle losses in a young persistent contrail, Geophs. Res. Lett., doi:10.1029/2018GL079390, 2018.

Kumjian, M. R.: The impact of precipitation physical processes on the polarimetric radar variables, Dissertation, University of Oklahoma, Norman Campus, https://hdl.handle.net/11244/319188, 2012

Kumjian, M. R., Khain, A. P., Benmoshe, N., Ilotoviz, E., Ryzhkov, A. V., and Phillips, V. T. J.: The anatomy and physics of $\mathrm{Z}_{\mathrm{DR}}$ columns: Investigating a polarimetric radar signature with a spectral bin microphysical model, Journal of Applied Meteorology and Climatology, 53, 1820-1843, 2014.

Le Treut, H. and Li, Z.-X.: Sensitivity of an atmospheric general circulation model to prescribed SST changes: Feedback effects associated with the simulation of cloud optical properties, Clim. Dyn., 5, 175-187, 1991.

Libbrecht, K. G.: The physics of snow crystals, Rep. Prog. Phys., 68, 855-895, doi:10.1088/0034-4885/68/4/R03, 2005.

Lohmann U. und E. Roeckner, Design and performance of a new cloud microphysics scheme developed for the ECHAM general circulation model. Clim. Dyn., 12, 557-572, 1996. 
Matsui, T., Dolan, B., Rutledge, S. A., Tao, W.-K., Iguchi, T., Barnum, J., and Lang, S. E.: POLARRIS: A POLArimetric

Radar Retrieval and Instrument Simulator, Journal of Geophysical Research: Atmospheres, 124, 4634-4657, doi:10.1029/2018JD028317, 2019.

Mellado, J.P., Stevens, B., Schmidt, H., and Peters, N.: Buoyancy reversal in cloud-top mixing layers, Q.J.R. Meteorol. Soc., 135: 963-978., doi:10.1002/qj.417, 2009.

686

Mendrok, J., Blahak, U., Snyder, J. C., and Carlin, J. T.: The polarimetric efficient modular volume scan radar forward operator Pol-EMVORADO, Geosci. Model Dev., 2021 (in preparation for this Special Issue).

Mishchenko, M. I.: Calculation of the amplitude matrix for a nonspherical particle in a fixed orientation, Appl. Opt. 39, 10261031 (2000).

Moisseev, D. N., Lautaportti, S., Tyynela, J., and Lim, S.: Dualpolarization radar signatures in snowstorms: Role of snowflake aggregation, J. Geophys. Res. Atmos., 120, 12 644-12 655, doi:10.1002/2015JD023884, 2015.

Morrison, H. and Milbrandt, J. A.: Parameterization of Cloud Microphysics Based on the Prediction of Bulk Ice Particle Properties. Part I: Scheme Description and Idealized Tests, Journal of the Atmospheric Sciences, 72(1), 287-311, 2015.

Mülmenstädt, J., Sourdeval, O., Delanoë, J., and Quaas, J.: Frequency of occurrence of rain from liquid-, mixed- and ice-phase clouds derived from A-Train satellite retrievals, Geophys. Res. Lett., 42, 6502-6509, doi:10.1002/2015GL064604, 2015.

Myagkov, A., Seifert, P., Bauer-Pfundstein, M., and Wandinger, U.: Cloud radar with hybrid mode towards estimation of shape and orientation of ice crystals, Atmos. Meas. Tech., 9, 469-489, doi:10.5194/amt-9-469-2016, 2016.

Neggers, R. A.: A dual mass flux framework for boundary layer convection. Part II: Clouds, J. Atmos. Sci., 66, 1489-1506, doi:10.1175/2008JAS2636.1, 2009.

Neto, J. D., Kneifel, S., Ori, D., Trömel, S., Handwerker, J., Bohn, B., Hermes, N., Mühlbauer, K., Lenefer, M., and Simmer, C.: The TRIple-frequency and Polarimetric radar Experiment for improving process observation of winter precipitation. Earth Syst. Sci. Data, 11, 845-863, doi: 10.5194/essd-11-845-2019, 2019. 
712 Nguyen, C., Wolde, M., Baibakov, K., and Korolev, A.: Detection and estimation of high ice water content using X- and W713 band dual-polarization airborne radar data, 38th Conf. on Radar Meteorology, Chicago, IL, Amer. Meteor. Soc., 89, 714 https://ams.confex.com/ams/38RADAR/webprogram/Paper321101.html, 2017.

715

Ori, D., V. Schemann, M. Karrer, J. Dias Neto, L. von Terzi, A. Seifert, and S. Kneifel: Evaluation of ice particle growth in ICON using statistics of multi-frequency Doppler cloud radar observations, Q. J. Roy. Meteor. Soc., 146: 3830- 3849. https://doi.org/10.1002/qj.3875,2020

Pincus, R. and Klein, S.: Unresolved spatial variability and microphysical process rates in large-scale models, J. Geophys. Res., 105, 27059 - 27065, 2000.

Putnam, B., Xue, M., Jung, Y., Snook, N., and Zhang, G.: Ensemble Kalman Filter Assimilation of Polarimetric Radar Observations for the 20 May 2013 Oklahoma Tornadic Supercell Case, Mon. Wea. Rev., 147, 2511-2533, doi:10.1175/MWRD-18-0251.1, 2019.

Reimann, L., Simmer, C., and Trömel, S.: Dual-polarimetric radar estimators of liquid water content over Germany. Accepted for Meteorol. Z. (Contrib. Atm. Sci.), doi:10.1127/metz/2021/1072, 2021.

Rosch, J., et al.: Analysis of diagnostic climate model cloud parameterisations using large-eddy simulations, Q. J. R. Meteorol. Soc., 141, 2199-2205, doi:10.1002/qj.2515, 2015.

Rotstayn, L. D.: On the tuning of autoconversion parameterizations in climate models, J. Geophys. Res., 105, 15,495-15,507, 2000.

Ryzhkov, A. V., Zrnic, D. S., and Gordon, B. A.: Polarimetric Method for Ice Water Content Determination. Journal of Applied Meteorology 37, 125-134, 1998.

Ryzhkov, A., Pinsky, M., Pokrovsky, A., and Khain, A.: Polarimetric Radar Observation Operator for a Cloud Model with Spectral Microphysics, J. Appl. Meteor. Climat., 50, 873-894, 2011. 
Ryzhkov, A., Zhang, P., Reeves, H., Kumjian, M., Tschallener, T., Trömel, S., and Simmer, C.: Quasi-vertical profiles - a new way to look at polarimetric radar data, J. Atmos. Oceanic Technol., 33, 551-562, doi: 10.1175/JTECH-D-15-0020.1, 2016.

Ryzhkov, A., Bukovcic, P., Murphy, A., Zhang, P., and McFarquhar, G.: Ice Microphysical Retrievals Using Polarimetric

Radar Data. In Proceedings of the 10th European Conference on Radar in Meteorology and Hydrology, Ede, The Netherlands,

Ryzhkov, A. and Zrnic, D.: Radar Polarimetry for Weather Observations, Springer Atmospheric Sciences, 486 pp., 2019.

Schinagl, K., Friederichs, P., Trömel, S., and Simmer, C.: Gamma Drop Size Distribution Assumptions in Bulk Model

Schrom, R. S. and Kumjian, M. R.: Bulk-Density Representations of Branched Planar Ice Crystals: Errors in the Polarimetric

Radar Variables, Journal of Applied Meteorology and Climatology, 57(2), 333-346, 2018.

Seifert, A. and Beheng, K. D.: A two-moment cloud microphysics parameterization for mixed-phase clouds. Part 1: Model description, Meteorol. Atmos. Phys., 92, 45-66, DOI: 10.1007/s00703-005-0112-4, 2006.

Shrestha, P., Sulis, M., Masbou, M., Kollet, S. and Simmer, C: A scale-consistent Terrestrial System Modeling Platform based on COSMO, CLM and ParFlow, Mon. Wea. Rev., 142, 3466-3483, doi: 10.1175/MWR-D-14-00029.1, 2014

Shrestha, P.: Clouds and vegetation modulate shallow groundwater table depth. Accepted for publication in Journal of Hydrometeorology, 2021

Shrestha, P., Mendrok, J., Pejcic, V., Trömel, S., and Blahak, U.: The impact of uncertainties in model microphysics, retrievals and forward operators on model evaluations in polarimetric radar space, Atmos. Chem. Phys., 2021 (close to submission for this Special Issue).

Simmer, C., Thiele-Eich, I., Masbou, M., Amelung, W., Crewell, S., Diekkrueger, B., Ewert, F., Hendricks Franssen, H.-J., Huisman, A. J., Kemna, A., Klitzsch, N., Kollet, S., Langensiepen, M., Löhnert, U., Rahman, M., Rascher, U., Schneider, K., 
Schween, J., Shao, Y., Shrestha, P., Stiebler, M., Sulis, M., Vanderborght, J., Vereecken, H., van der Kruk, J., Zerenner, T., and Waldhoff, G.: Monitoring and Modeling the Terrestrial System from Pores to Catchments - the Transregional Collaborative Research Center on Patterns in the Soil-Vegetation-Atmosphere System, Bulletin of the American Meteorological Society, 96, 1765-1787. doi: http://dx.doi.org/10.1175/BAMS-D-13-00134.1, 2015.

Simmer, C., Adrian, G., Jones, S., Wirth, V., Goeber, M., Hohenegger, C., Janjic, T., Keller, J., Ohlwein, C., Seifert, A., Meteorological Society, p.1057-1068, DOI: http://dx.doi.org/10.1175/BAMS-D-13-00227.1, 2014

Smith, R. N.: A scheme for predicting layer clouds and their water content in a general circulation model, Q. J. R. Meteorol.

Snyder, J.C., Ryzhkov, A.V., Kumjian, M.R., Khain, A.P., and Picca, J.C.: A ZDR column detection algorithm to examine convective storm updrafts, Weather and Forecasting, 30, 1819-1844, 2015.

Sommeria, G. and Deardorff, J. W.: Subgrid-scale condensation models of non-precipitating clouds, J. Atmos. Sci., 34, 344$355,1977$.

Sourdeval, O., Gryspeerdt, E., Krämer, M., Goren, T., Delanoë, J., Afchine, A., Hemmer, F., and Quaas, J.: Ice crystal number concentration estimates from lidar-radar satellite remote sensing - Part 1: Method and evaluation, Atmos. Chem. Phys., 18, 14327-14350, doi: 10.5194/acp-18-14327-2018, 2018.

Stevens, B., Acquistapace, C., Hansen, A., Heinze, R., Klinger, C., Klocke, D., Schubotz, W., Windmiller, J., Adamidis, P., Arka, I., Barlakas, V., Biercamp, J., Brueck, M., Brune, S., Buehler, S., Burkhardt, U., Cioni, G., Costa-Surós, M., Crewell, S., Crueger, T., Deneke, H., Friederichs, P., Carbajal Henken, C., Hohenegger, C., Jacob, M., Jakub, F., Kalthoff, N., Köhler, Meteorol. Soc. Japan, 98, doi:10.2151/jmsj. 2020-021, 2020. 
Stevens, B. and Feingold, G.: Untangling Aerosol Effects on Clouds and Precipitation in a Buffered System, Nature, 461, 607613, 2009.

Sundqvist, H., et al., Condensation and cloud parameterization studies with a mesoscale numerical weather prediction model, Mon. Weather Rev., 117, 1641-1657, 1989.

Takahashi, T.: High ice crystal production in winter cumuli over the Japan Sea, Geophysical research letters, 20.6, 451-454, 1993.

Takahashi, T., Yoshihiro N., and Yuzuru K.: Possible high ice particle production during graupel-graupel collisions, Journal of the atmospheric sciences, 52.24, 4523-4527, 1995.

Takahashi, T.: Influence of liquid water content and temperature on the form and growth of branched planar snow crystals in a cloud. Journal of the Atmospheric Sciences, 71.11, 4127-4142, 2014.

Tiedtke, M.: Representation of clouds in large scale models, Mon. Weather Rev., 121, 3040-3061, 1993.

Tompkins, A.: A prognostic parameterization for the subgrid-scale variability of water vapor and clouds in large-scale models and its use to diagnose cloud cover, J. Atmos. Sci., 59:1917- 1942, 2002.

Trömel, S., Quaas, J., Crewell, S., Bott, A., and Simmer, C.: Polarimetric Radar Observations Meet Atmospheric Modelling.

(IRS), Bonn, doi: 10.23919/IRS.2018.8448121,

URL:

Trömel, S., Ryzhkov, A. V., Hickman, B., Mühlbauer, K., and Simmer, C.: Polarimetric Radar Variables in the Layers of

Trömel, S., A. V. Ryzhkov, P. Zhang, and C. Simmer: The microphysical information of backscatter differential phase $\delta$ in the

Voigt, C., Schumann, U., Jurkat, T., Schäuble, D., Schlager, H., Petzold, A., Gayet, J.-F., Krämer, M., Schneider, J., Borrmann, S., Schmale, J., Jessberger, P., Hamburger, T., Lichtenstern, M., Scheibe, M., Gourbeyre, C., Meyer, J., Kübbeler, M., Frey, 
W., Kalesse, H., Butler, T., Lawrence, M. G., Holzäpfel, F., Arnold, F., Wendisch, M., Döpelheuer, A., Gottschaldt, K., Baumann, R., Zöger, M., Sölch, I., Rautenhaus, M., and Dörnbrack, A.: In-situ observations of young contrails - overview and selected results from the CONCERT campaign, Atmos. Chem. Phys., 10, 9039-9056, https://doi.org/10.5194/acp-109039-2010, 2010.

Voigt, C., Jeßberger, P., Jurkat, T., Kaufmann, S., Baumann, R., Schlager, H., Bobrowski, N., Guffirda, G., and Salerno, G.:

Evolution of $\mathrm{CO}_{2}, \mathrm{SO}_{2}, \mathrm{HCl}$ and $\mathrm{HNO}_{3}$ in the volcanic plumes from Etna, Geophys. Res. Lett., 41, doi:10.1002/2013GL058974, 2014.

852

Voigt, C., Schumann, U., Minikin, A., Abdelmonem, A., Afchine, A., Borrmann, S., Boettcher, M., Buchholz, B., Bugliaro, L., Costa, A., Curtius, J., Dollner, M., Dörnbrack, A., Dreiling, V., Ebert, V., Ehrlich, A., Fix, A., Forster, L., Frank, F., Fütterer, D., Giez, A., Graf, K., Grooß, J., Groß, S., Heimerl, K., Heinold, B., Hüneke, T., Järvinen, E., Jurkat, T., Kaufmann, S., Kenntner, M., Klingebiel, M., Klimach, T., Kohl, R., Krämer, M., Krisna, T. C., Luebke, A., Mayer, B., Mertes, S., Molleker, S., Petzold, A., Pfeilsticker, K., Port, M., Rapp, M., Reutter, P., Rolf, C., Rose, D., Sauer, D., Schäfler, A., Schlage, R., Schnaiter, M., Schneider, J., Spelten, N., Spichtinger, P., Stock, P., Walser, A., Weigel, R., Weinzierl, B., Wendisch, M., Werner, F., Wernli, H., Wirth, M., Zahn, A., Ziereis, H., and Zöger, M.; ML-CIRRUS: The Airborne Experiment on Natural Cirrus and Contrail Cirrus with the High-Altitude Long-Range Research Aircraft HALO, Bulletin of the American Meteorological Society, 98(2), 271-288, doi:bams-d-15-00213.1, 2017.

Voigt, C., Lelieveld, J., Schlager, H., Schneider, J., Sauer, D., Meerkötter, R., Pöhlker, M., Bugliaro, L., Curtius, J., Erbertseder, T., Hahn, V., Jöckel, P., Li, Q., Marsing, A., Mertens, M., Pöhlker, C., Pöschl, U., Pozzer, A., Tomsche, L., and Schumann, U.: Aerosol and Cloud Changes during the Corona Lockdown in 2020 - First highlights from the BLUESKY campaign; EGU21-13134, https://meetingorganizer.copernicus.org/EGU21/session/40818, 2021.

Weissmann, M., M. Göber, C. Hohenegger, T. Janjic, J. Keller, C. Ohlwein, A. Seifert, S. Trömel, T. Ulbrich, K. Wapler, C. Bollmeyer, H. Deneke: The Hans-Ertel Centre for Weather Research - Research objectives and highlights from its first three years. Meteorol. Z., 23(3), 193 - 208, 2014.

Wendisch, M., Pöschl, U., Andreae, M. O., Machado, L. A. T., Albrecht, R., Schlager, H., Rosenfeld, D., Martin, S. T., Abdelmonem, A., Afchine, A., Araùjo, A. C., Artaxo, P., Aufmhoff, H., Barbosa, H. M. J., Borrmann, S., Braga, R., Buchholz, B., Cecchini, M. A., Costa, A., Curtius, J., Dollner, M., Dorf, M., Dreiling, V., Ebert, V., Ehrlich, A., Ewald, F., Fisch, G., Fix, A., Frank, F., Fütterer, D., Heckl, C., Heidelberg, F., Hüneke, T., Jäkel, E., Järvinen, E., Jurkat, T., Kanter, S., Kästner, U., Kenntner, M., Kesselmeier, J., Klimach, T., Knecht, M., Kohl, R., Kölling, T., Krämer, M., Krüger, M., Krisna, T. C., Lavric, J. V., Longo, K., Mahnke, C., Manzi, A. O., Mayer, B., Mertes, S., Minikin, A., Molleker, S., Münch, S., Nillius, B., Pfeilsticker, K., Pöhlker, C., Roiger, A., Rose, D., Rosenow, D., Sauer, D., Schnaiter, M., Schneider, J., Schulz, C., de Souza, 
R. A. F., Spanu, A., Stock, P., Vila, D., Voigt, C., Walser, A., Walter, D., Weigel, R., Weinzierl, B., Werner, F., Yamasoe, M. A., Ziereis, H., Zinner, T., and Zöger, M.: ACRIDICON-CHUVA Campaign: Studying Tropical Deep Convective Clouds and Precipitation over Amazonia Using the New German Research Aircraft HALO, Bulletin of the American Meteorological Society, 97(10), 1885-1908, doi:bams-d-14-00255.1, 2016.

Wolfensberger, D. and Berne, A.: From model to radar variables: a new forward polarimetric radar operator for COSMO, Atmos. Meas. Tech., 11, 3883-3916, doi: 10.5194/amt-11-3883-2018, 2018.

Xie, X., Evaristo, R., Trömel, S., Saavedra, P., Simmer, C., and Ryzhkov, A.: Radar Observation of Evaporation and Implications for Quantitative Precipitation and Cooling Rate Estimation, J. Atmos. Oceanic Technol. 33(8), 1779-1792, doi:10.1175/JTECH-D-15-0244.1, 2016.

Xie, X., Shrestha, P., Mendrok, J., Carlin, J., Trömel, S., and Blahak, U.: Bonn Polarimetric Radar forward Operator (B-PRO),

Zängl, G., et al.: The ICON (icosahedral non-hydrostatic) modelling framework of DWD and MPI-M: Description of the nonhydrostatic dynamical core; Quart. J.Roy. Meteorol. Soc., 141, 563-579, 2015.

Zeng, Y., Janjic, T., Lozar, A. de, Welzbacher, C. A., Blahak, U., and Seifert, A.: Assimilating radar radial wind and reflectivity data in an idealized setup of the COSMO-KENDA system, Atmospheric Research, 249, 105282, doi:10.1016/j.atmosres.2020.105282, 2021.

Zeng, Y., Janjic, T., Lozar, A. de, Rasp, S., Blahak, U., Seifert, A., and Craig, G. C.: Comparison of methods accounting for subgrid-scale model error in convective-scale data assimilation, Mon. Wea. Rev., 148, 2457-2477, 2020.

Zeng Y., Janjic, T., Sommer, M., Lozar, A. de, Blahak, U., and Seifert, A.: Representation of model error in convective-scale data assimilation: additive noise based on model truncation error, J. Advances in Modelling Earth Systems, 11, 752-770, 2019. 
https://doi.org/10.5194/acp-2021-346

Preprint. Discussion started: 21 May 2021

(c) Author(s) 2021. CC BY 4.0 License.

(c) (i)

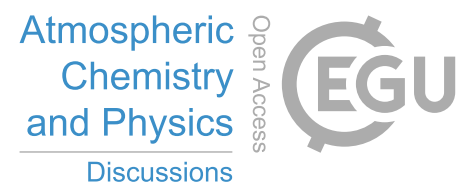

906 Zeng, Y., Blahak, U., and Jerger, D.: An efficient modular volume-scanning radar forward operator for NWP models:

907 description and coupling to the COSMO model, Quarterly Journal of the Royal Meteorological Society, 142(701), 3234-3256,

$908 \quad 2016$

909

910 Zhu, K., Xue, M., Ouyang, K., and Jung, Y.: Assimilating polarimetric radar data with an ensemble Kalman filter: OSSEs with

911 a tornadic supercell storm simulated with a two-moment microphysics scheme, Q. J. R. Meteorol. Soc., 146: 1880- 1900,

912 doi:10.1002/qj.3772, 2020.

913

914 

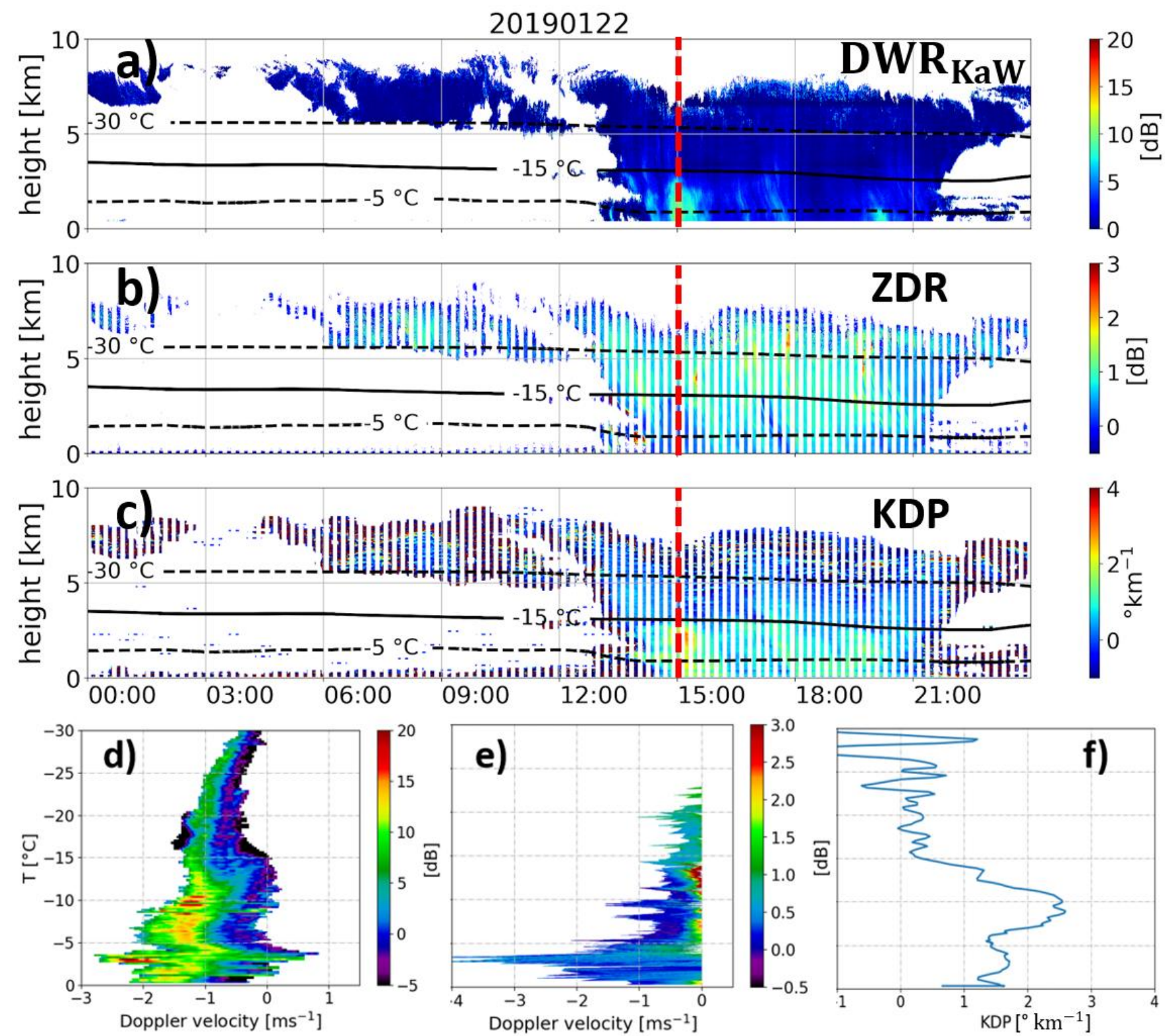

Figure 1: Observations at JOYCE-CF shows a) DWRKaW, b) $\mathrm{Z}_{\mathrm{DR}}$ (measured at a $30^{\circ}$ elevation angle), c) $\mathrm{K}_{\mathrm{DP}}$ (also measured at $30^{\circ}$

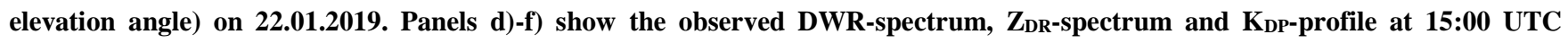



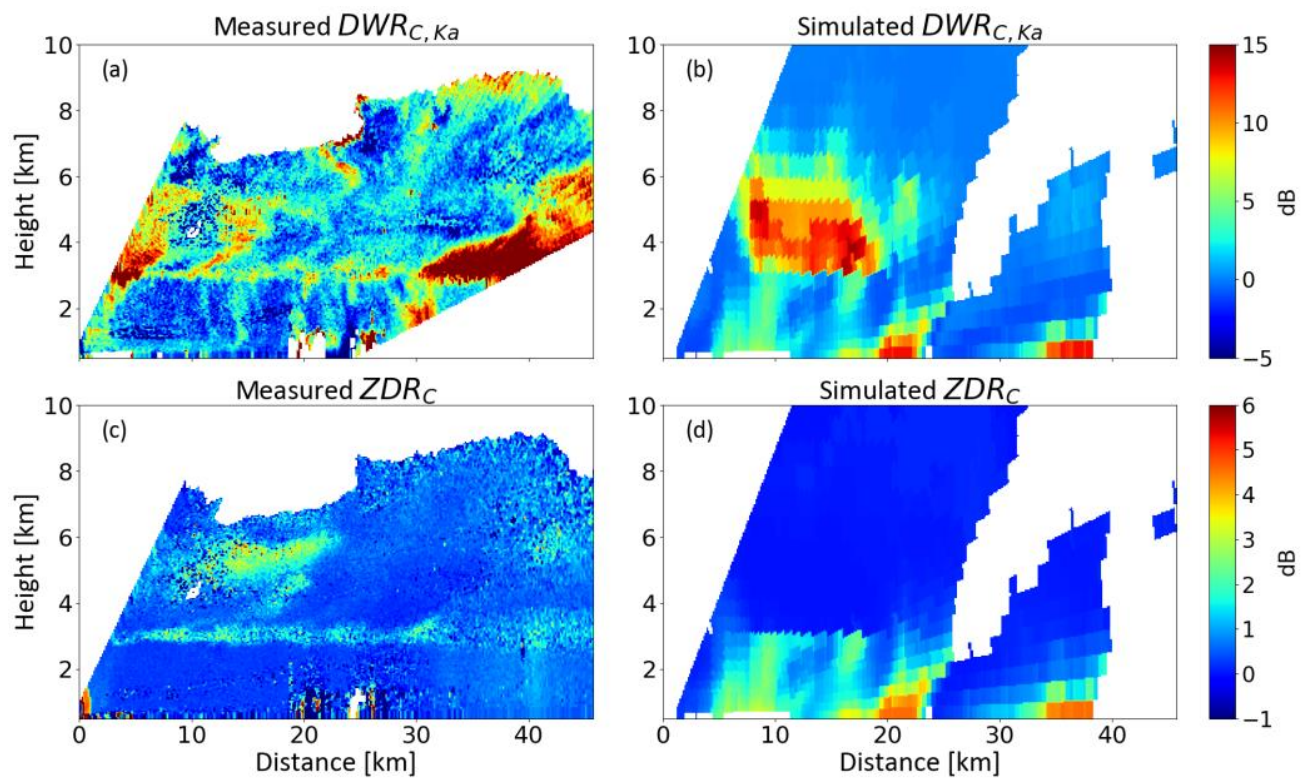

Figure 2 (a) Dual-wavelength ratio between the C-band POLDIRAD and Ka-band miraMACS measurements on the 7th July 2019, simulated $Z_{D R}$ of a comparable, but not identical, precipitation event using the P3 scheme (Morrison and Milbrandt, 2015).
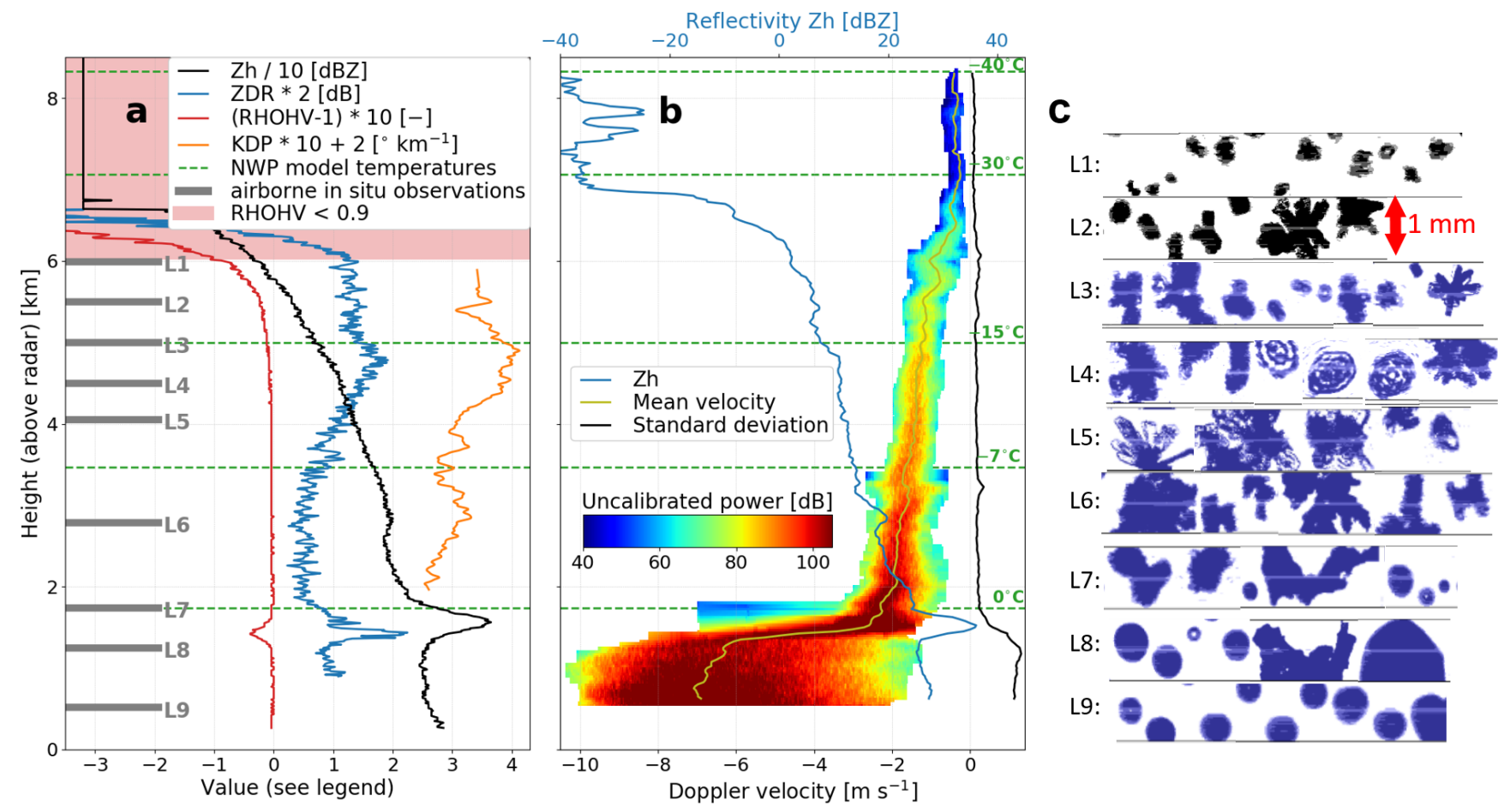
Figure 3: Measurements of slant-viewing and zenith-pointing polarimetric C-band weather radar scans with NWP model based temperature levels and airborne in-situ observations: (a) quasi-vertical profiles (QVPs) of radar reflectivity $Z_{\mathrm{H}}$, differential reflectivity $Z_{\mathrm{DR}}$, copolar cross-channel correlation coefficient $\rho_{\mathrm{HV}}$, and the specific differential phase $K_{\mathrm{DP}}$ estimated from (noisy) measurements of the differential phase by aggressive filtering above the melting layer; (b) average Doppler spectra from a $15 \mathrm{~s}$ birdbath scan and corresponding first 3 moments at each radar bin height: reflectivity, power-weighted mean velocity and standard deviation; (c) in situ particle images (downward-looking projection images) collected at altitudes L1 to L9.
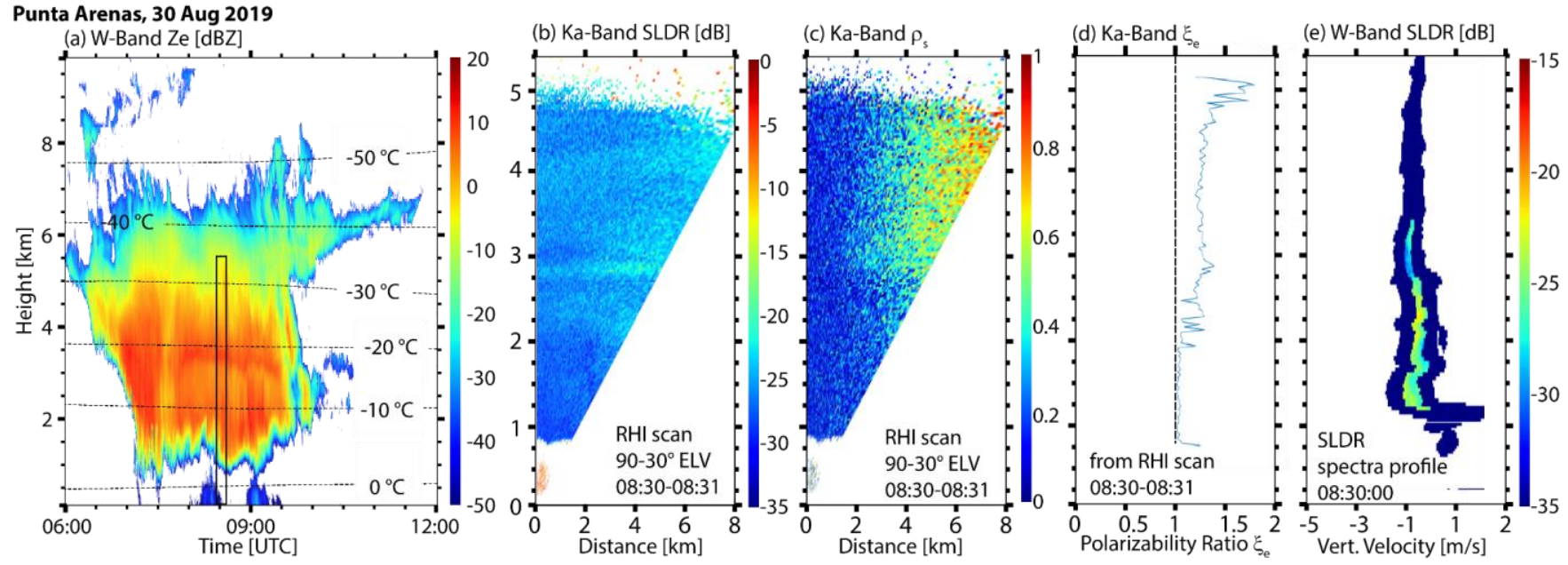

Figure 4: Case study of a deep mixed-phase cloud event observed with multiwavelength polarimetric cloud radars at Punta Arenas, Chile, on 30 August 2019. (a) vertical-stare W-Band (94-GHz) radar reflectivity factor Ze and isolines of modelled air temperature, (b) and (c) Ka-Band (35-GHz) RHI scans $\left(90^{\circ}-30^{\circ}\right.$ elevation) of slanted linear depolarization ratio SLDR and co-cross correlation coefficient in the slanted basis $\rho_{s}$, respectively, from 08:30-08:31 UTC, (d) profile of the shape index polarizability ratio $\left(\xi_{\mathrm{e}}\right)$ obtained from the RHI scans shown in (b) and (c), and (e) height spectrogram (at 90 elevation) of W-Band SLDR from 08:30:00 UTC. The time and height frame of panels (b-e) is indicated by the black rectangle in (a). 
a)

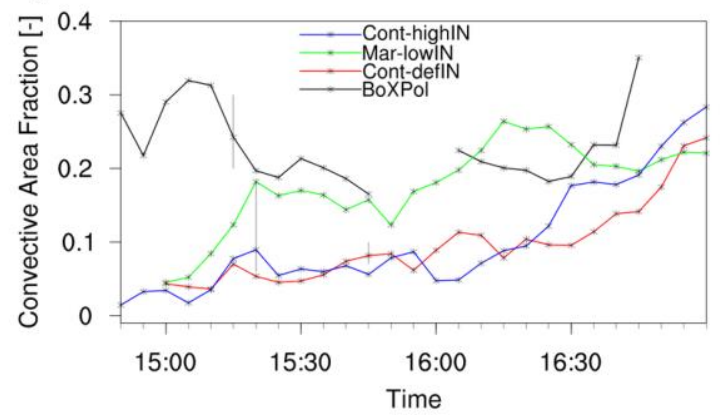

c)

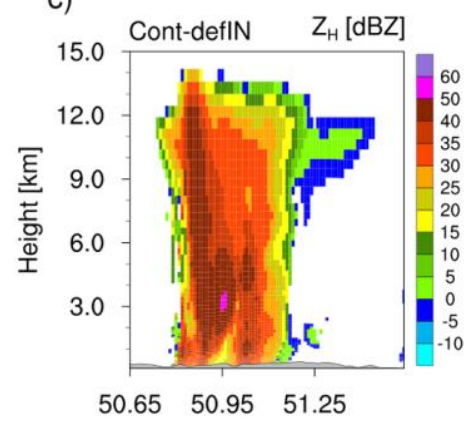

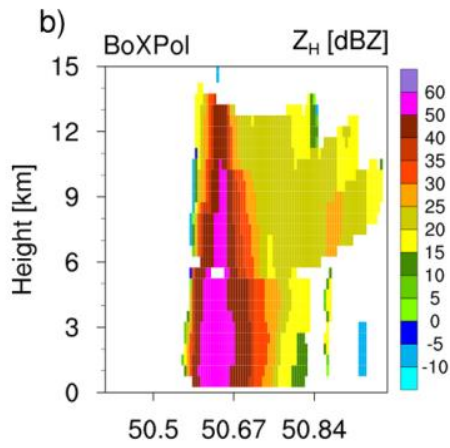

d)

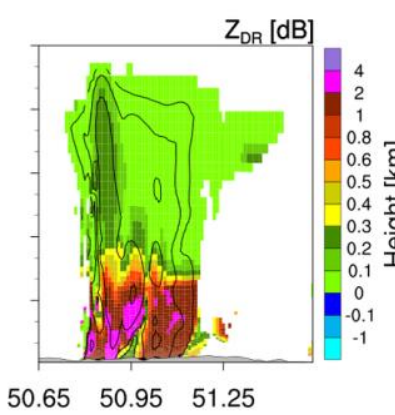

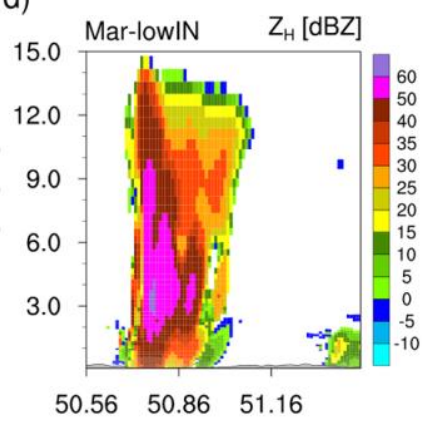
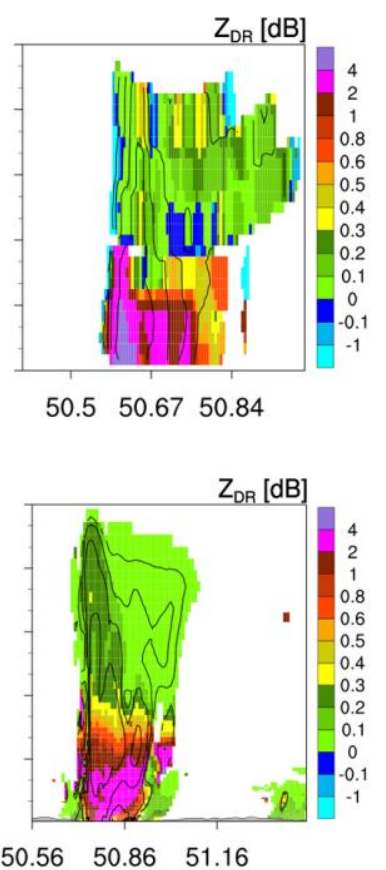

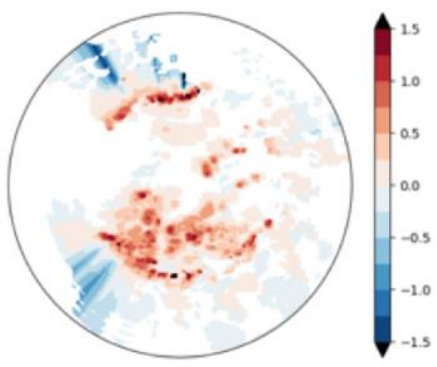

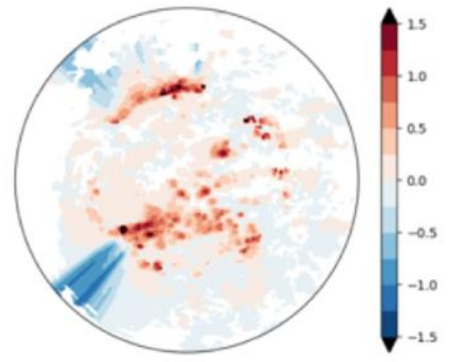

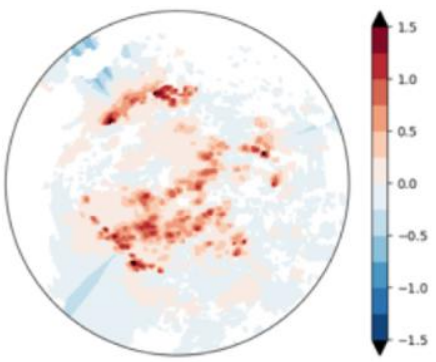

Figure 6: Synthetic PPI of $Z_{D R}$ at 0.5 deg elevation for the DWD radar site Neuheilenbach based on the analysis obtained for June (left), large plus unresolved scales uncertainty (middle) and in addition the use of the warm bubble approach (right). 

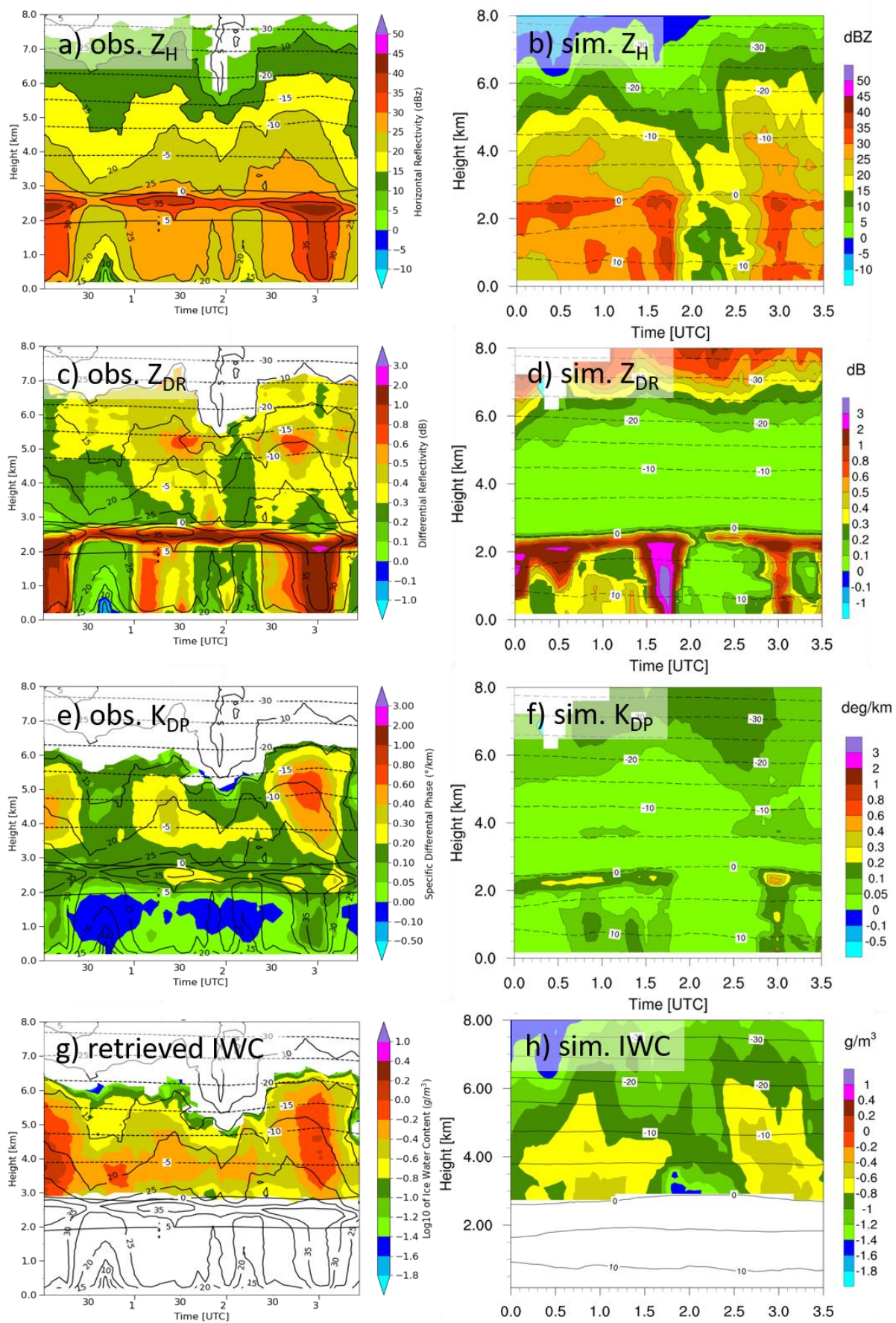

958 Figure 7: Quasi-vertical profiles (QVPs) of observed (left column) and imulated polarimetric radar variables (right column), i.e.

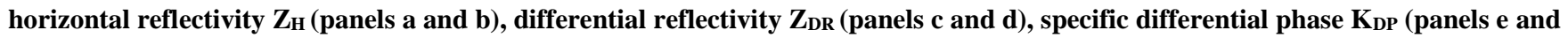
f), together radar-retrieved ice water content (IWC, panel g) and simulated IWC (panel h). The QVPs show a stratiform rain event 
https://doi.org/10.5194/acp-2021-346

Preprint. Discussion started: 21 May 2021

(c) Author(s) 2021. CC BY 4.0 License.

(c) (i)

961 observed on 7 October 2014 between 0 and 3:30 UTC with the polarimetric X-band radar in Bonn, BoXPol, and simulated with
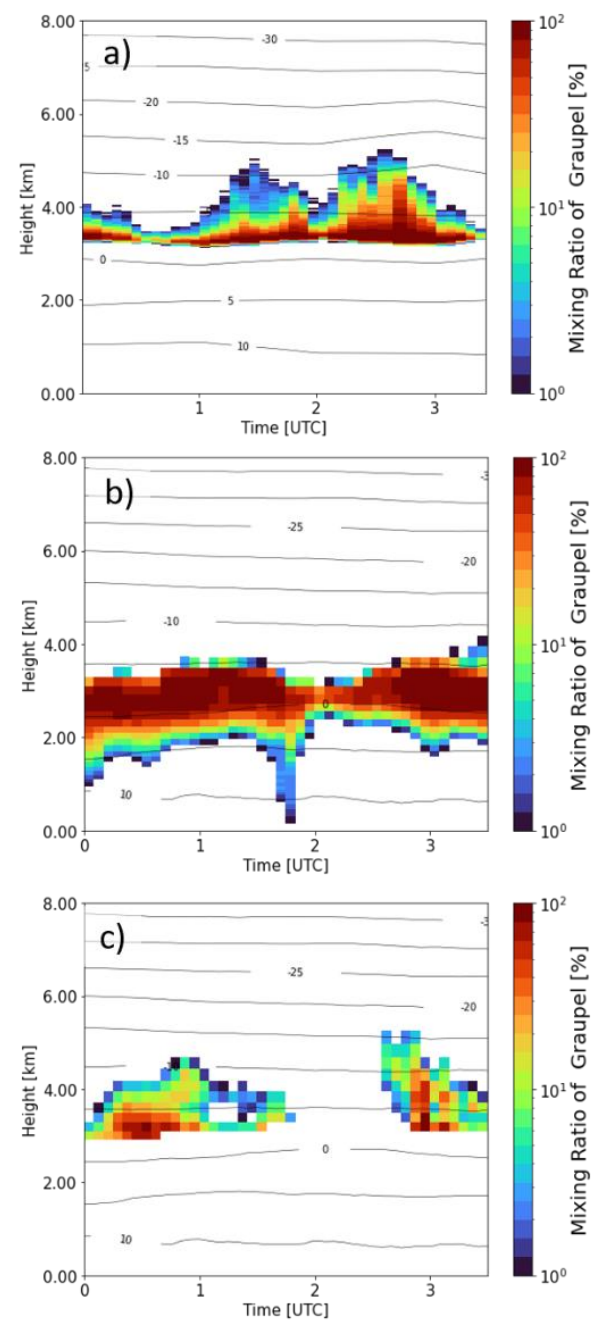

965 Figure 8: Retrieved and simulated graupel mixing ratios, defined as the percentage of graupel in the total hydrometeor mass, for the stratiform rain event shown in Fig. 7 (7 October 2014, 0-3:30 UTC). An advanced hydrometeor classification and quantification algorithm has been applied to polarimetric BoXPol measurement (panel a) and to simulated radar variables based on COSMO simulations (panel c) and compared to the COSMO-simulated graupel mixing (panel b). 

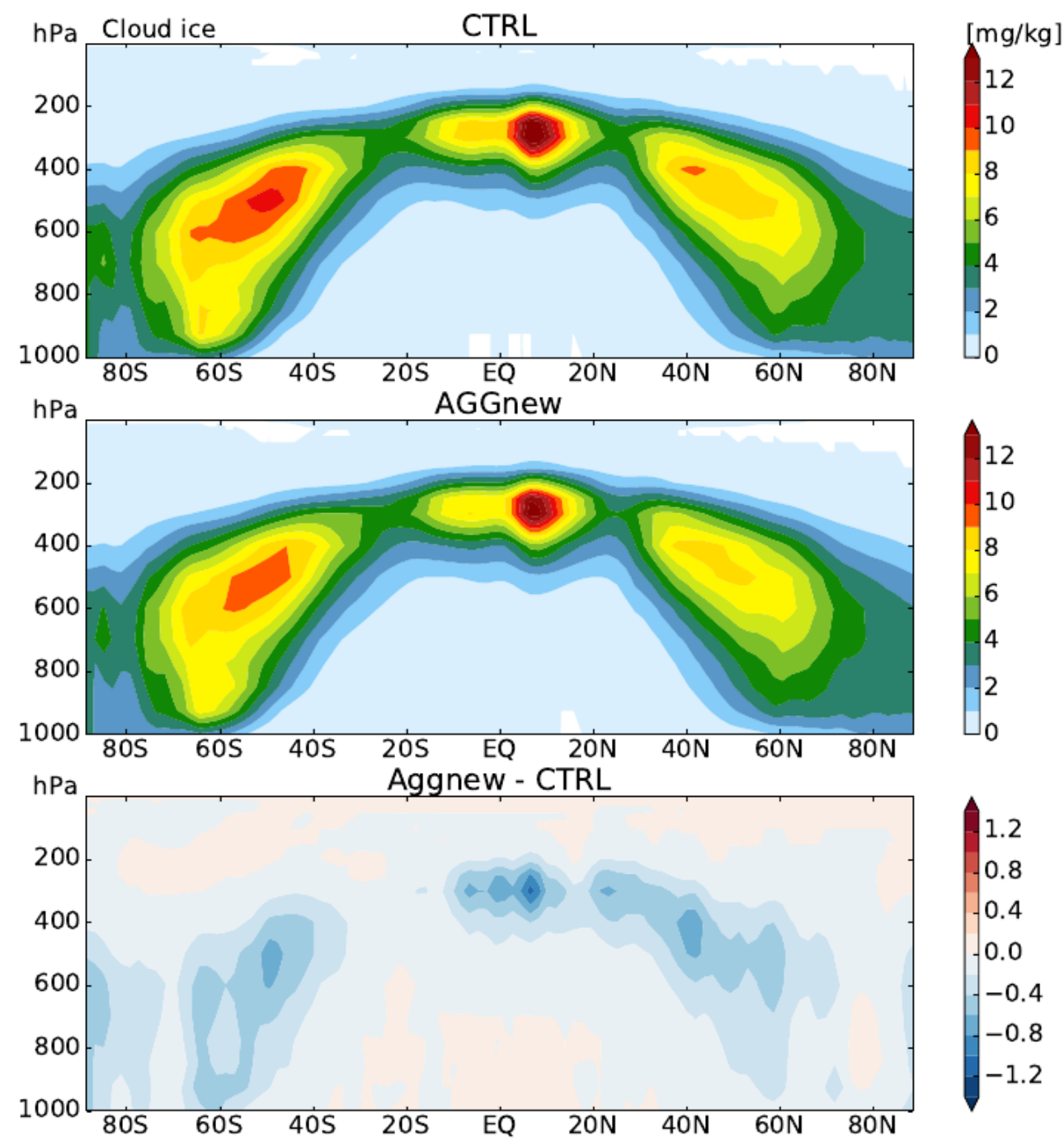

Figure 9: Specific ice water, $q_{i}$, $\left[\mathrm{g} \mathrm{kg}^{-1}\right]$ as zonal, annual mean for (top) standard ICON GCM output, (middle) aggregation parameterization revised as stochastic parameterization drawing from the $q_{\mathrm{i}}$ subgrid-variability PDF, and (bottom) difference between the two. 